Argonne

ANL/DIS-21/4

\title{
Bridge Seismic Screening Tool (BSST), Version 2.0
}

Technical Report

Decision and Infrastructure Sciences Division 


\title{
Acknowledgement
}

This report has been prepared by Argonne National Laboratory (Argonne). Argonne is a U.S. Department of Energy laboratory managed by UChicago Argonne, LLC under contract DE-AC02-06CH11357. This study was sponsored by the Cybersecurity and Infrastructure Security Agency (CISA) Regional Resiliency Assessment Program. We would like to thank Patrick Massey, Chass Jones, Jason Osleson and Jaysen Goodwin at CISA for their support and guidance throughout this effort.

\author{
About Argonne National Laboratory \\ Argonne is a U.S. Department of Energy laboratory managed by UChicago Argonne, LLC \\ under contract DE-AC02-06CH11357. The Laboratory's main facility is outside Chicago, at \\ 9700 South Cass Avenue, Argonne, Illinois 60439. For information about Argonne \\ and its pioneering science and technology programs, see www.anl.gov.
}

\section{DOCUMENT AVAILABILITY}

Online Access: U.S. Department of Energy (DOE) reports produced after 1991 and a growing number of pre-1991 documents are available free at OSTI.GOV (http://www.osti.gov/), a service of the US Dept. of Energy's Office of Scientific and Technical Information.

Reports not in digital format may be purchased by the public from the National Technical Information Service (NTIS):

U.S. Department of Commerce

National Technical Information Service

5301 Shawnee Rd

Alexandria, VA 22312

www.ntis.gov

Phone: (800) 553-NTIS (6847) or (703) 605-6000

Fax: (703) 605-6900

Email: orders@ntis.gov

Reports not in digital format are available to DOE and DOE contractors from the

Office of Scientific and Technical Information (OSTI):

U.S. Department of Energy

Office of Scientific and Technical Information

P.O. Box 62

Oak Ridge, TN 37831-0062

www.osti.gov

Phone: (865) 576-8401

Fax: (865) 576-5728

Email: reports@osti.gov 


\section{Bridge Seismic Screening Tool (BSST), Version 2.0}

Technical Report

Josh Bergerson, Scott Schlueter, Kyle Feffer, Patrick Wilkey and Thomas Wall Decision and Infrastructure Sciences Division, Argonne National Laboratory 


\section{Bridge Seismic Screening Tool (BSST), Version 2.0 - Technical Report}

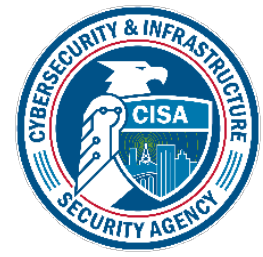

August 2021 


\section{Table of Contents}

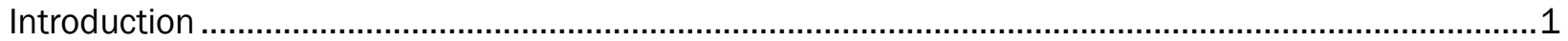

Regional Stakeholder Engagement and Acknowledgements ..........................................................

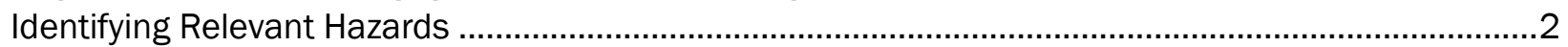

CSZ Earthquake Ground Motion ...........................................................................................

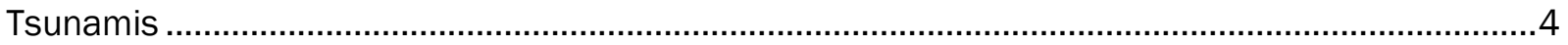

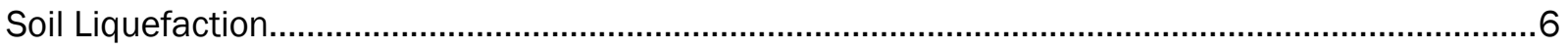

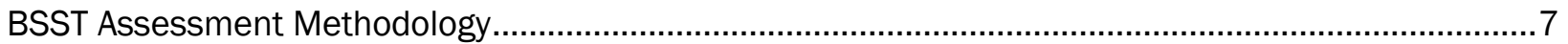

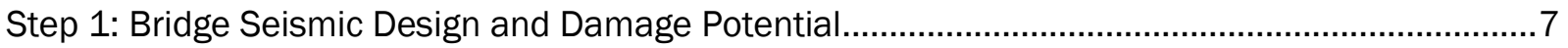

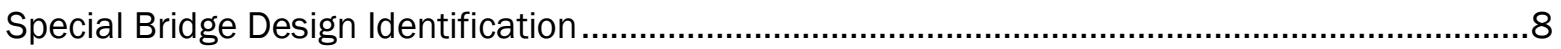

Bridge Seismic Design Considerations ................................................................................

Step 2: Geological Hazard Considerations ................................................................................. 10

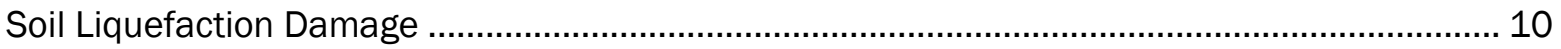

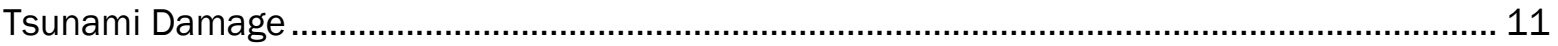

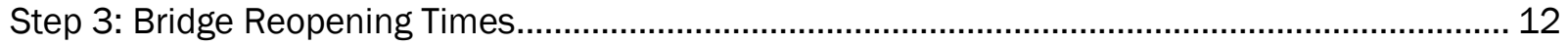

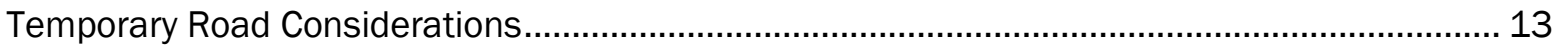

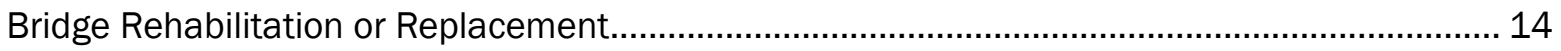

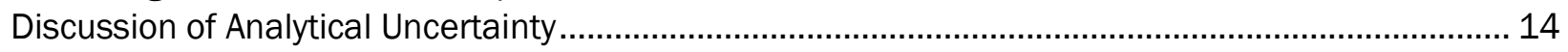

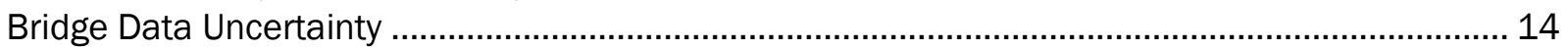

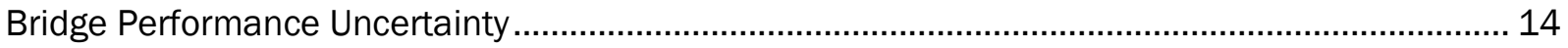

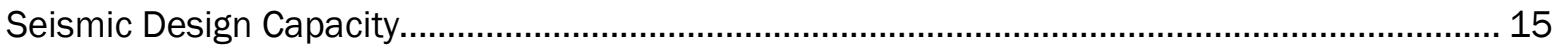

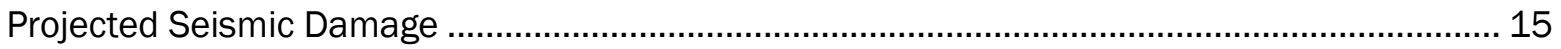

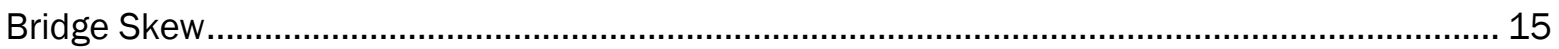

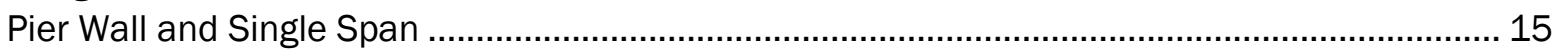

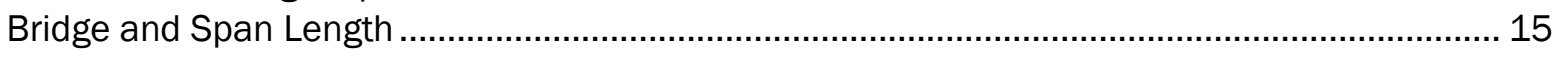

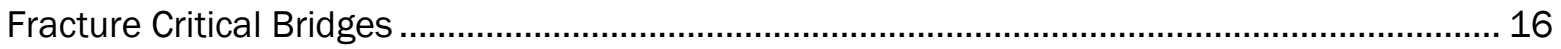

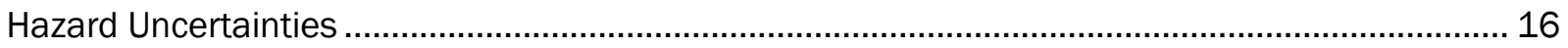

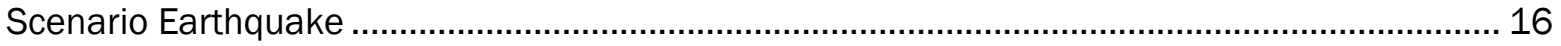

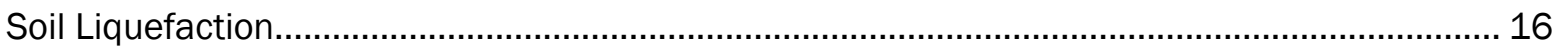

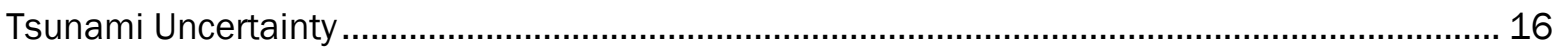

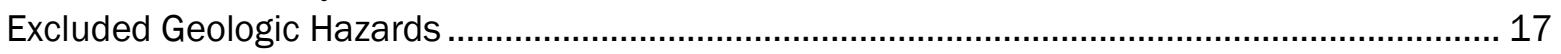

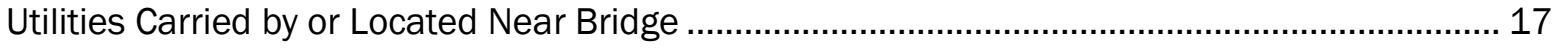

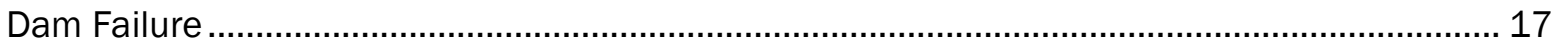

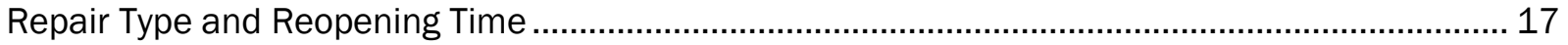

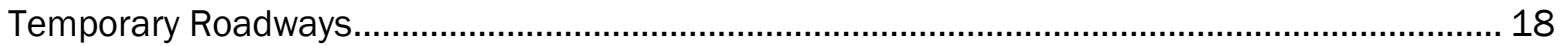

Route Service Restoration Time Uncertainty .................................................................... 18

Bridge Seismic Screening Results ......................................................................................... 19

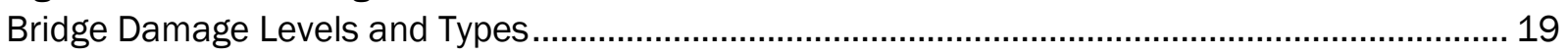

Severe Damage

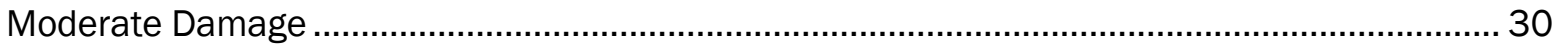

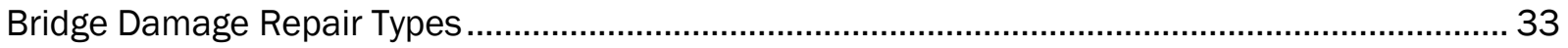

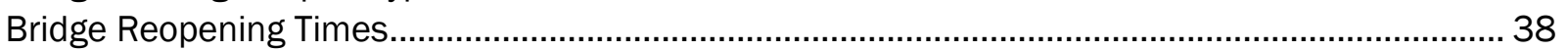

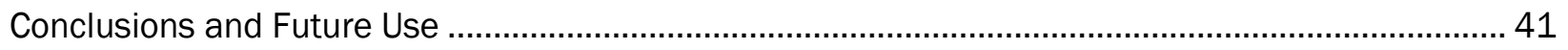

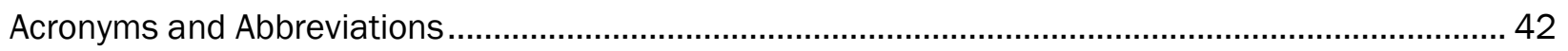

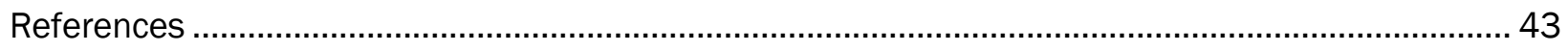

Appendix A: Major Revisions from BSST Version 1 to BSST Version 2 .............................................. 45 


\section{Figures}

1. Projected PGA for Oregon under the USGS M9.0 CSZ Scenario................................................... 3

2. Inundation Area of Oregon DOGAMI XXL 1,200-year Tsunami Scenario. ......................................... 5

3. BSST Methodology.............................................................................................................. 7

4. Bridge Seismic Screening Tool (BSST) Projected Damage Severity for State-owned Bridges in Oregon from the CSZ Scenario Earthquake. ........................................................................... 24

5. BSST Projected Damage Severity for Non-state-owned Bridges in Oregon from the CSZ Scenario

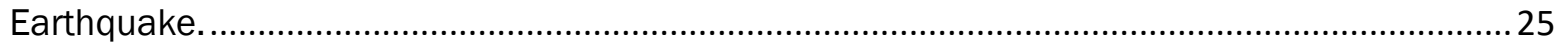

6. State-owned Bridges in Oregon Projected by BSST to Experience Severe Damage from the CSZ Scenario Earthquake Due to Inadequate Seismic Design. ..........................................................26

7. Non-state-owned Bridges in Oregon Projected by BSST to Experience Severe Damage from the CSZ Scenario Earthquake Due to Inadequate Seismic Design.

8. BSST Projected Liquefaction Damage for State-owned Bridges in Oregon from the CSZ Scenario

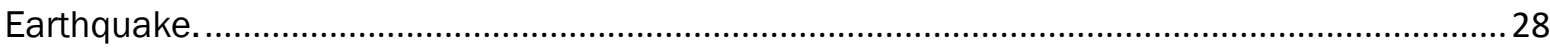

9. BSST Projected Liquefaction Damage for Non-state-owned Bridges in Oregon from the CSZ

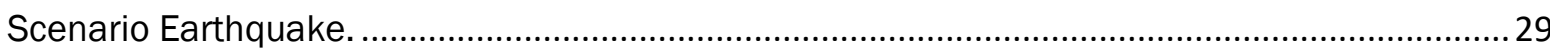

10. BSST Projected Tsunami Damage for Bridges in Oregon from the CSZ Scenario Earthquake...... 30

11. BSST Projected Moderate Shaking Damage for State-owned Bridges in Oregon from the CSZ

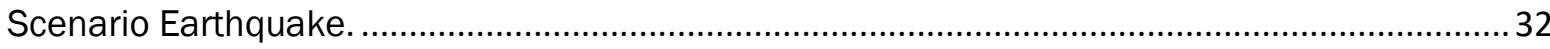

12. BSST Projected Moderate Shaking Damage for Non-state-owned Bridges in Oregon from the CSZ Scenario Earthquake.

13. State-owned Bridges in Oregon Projected by the BSST to Experience Severe Damage Requiring Construction of a New Bridge after the CSZ Scenario Earthquake.

14. State-owned Bridges in Oregon Projected by the BSST to Not Require the Construction of a New Bridge after the CSZ Scenario Earthquake.

15. Non-state-owned Bridges in Oregon Projected by the BSST to Experience Severe Damage Requiring Construction of a New Bridge after the CSZ Scenario Earthquake.

16. Non-state-owned Bridges in Oregon Projected by the BSST to Not Require the Construction of a New Bridge after the CSZ Scenario Earthquake.

17. BSST Projected Reopening Times for State-owned Bridges in Oregon after the CSZ Scenario Earthquake.

18. BSST Projected Reopening Times for Non-state-owned Bridges in Oregon after the CSZ Scenario Earthquake.

\section{Tables}

1. Determination of Oregon Bridge Seismic Design Capacity Based on Bridge Design Year.............. 10

2. Bridge Reopening Times and Repair Types Based on Damage and Bridge Length........................ 13

3. Projected Bridge Damage Types and Levels from CSZ Scenario Earthquake.................................20

4. Projected Bridge Repair Types after CSZ Scenario Earthquake...................................................... 34

5. Projected Bridge Reopening Times after CSZ Scenario Earthquake............................................... 39 


\section{Introduction}

The Regional Resiliency Assessment Program (RRAP) is a cooperative assessment of specific critical infrastructure within a designated geographic area and a regional analysis of the surrounding infrastructure that addresses a range of infrastructure resilience issues that could have regionally and nationally significant consequences. In 2018, DHS's Cybersecurity and Infrastructure Security Agency (CISA) sponsored the Oregon Transportation Systems RRAP project in coordination with the Office of the Governor (under the oversight of the state resilience officer), the Oregon Office of Emergency Management (OEM), the Oregon Department of Transportation (ODOT), and other regional stakeholders (CISA 2021). This project focuses on assessing the impacts of a Cascadia Subduction Zone (CSZ) earthquake on state transportation systems and, in particular, how those impacts may affect the ability of emergency response efforts to move supplies into the region. The intended outcome of this analysis is the prioritization of transportation routes and modes for additional planning, investment, hardening, or other activities to enhance their resilience-and therefore, to enhance their ability to support response and recovery efforts following a CSZ earthquake.

An important part of this transportation system-level assessment has been to assess the seismic vulnerability of the state highway system. In doing so, the RRAP project team used the Bridge Seismic Screening Tool (BSST) to assess, at a system-level, the potential impacts that a CSZ earthquake could have on state highway bridges (Bergerson et al. 2019). ${ }^{1}$ Argonne National Laboratory (Argonne), in collaboration with the Washington State Department of Transportation (WSDOT), originally developed the BSST as part of the 2017 Washington State Transportation Systems RRAP project, a sister project to the 2018 Oregon Transportation Systems RRAP project. Argonne updated the BSST during this more recent project in Oregon based on feedback from stakeholders and subject matter experts (SMEs) on the original version of the tool. The first step in the BSST is to assess the seismic vulnerability of roadway bridges following a CSZ earthquake to determine a projected or potential damage state. Damage states then help determine approximate reopening times for bridge crossings. ${ }^{2}$ This document provides details on the BSST methodology, the implementation of that tool to analyze the projected damage incurred in a CSZ earthquake scenario, and the determination of corresponding reopening times of interstate, state highway, and local bridges following such an event.

\section{Regional Stakeholder Engagement}

Collaboration with state and regional experts was fundamental to the initial development and subsequent refinement of the BSST. Experts from the WSDOT Bridge and Structures Office, Bridge Preservation Program, and State Materials Laboratory provided significant technical input and review throughout the initial development of the BSST. In particular, the DeWayne Wilson and Glen Scroggins from the WSDOT Bridge \& Structures Office reviewed and offered methodological input on numerous early iterations of the BSST framework during its development. They also reviewed initial and final results of the BSST analysis of interstate and state highway bridges in Washington State during the 2017 Washington State Transportation Systems RRAP project (CISA 2019). The RRAP team is grateful for their guidance and support that was fundamental to the initial BSST development.

\footnotetext{
${ }^{1}$ This tool does not conduct a detailed asset-level engineering analysis of individual structures; it is not intended to predict or provide a detailed or specific assessment of direct seismic and seismic-related impacts on individual bridges from a CSZ event, but rather to inform a system- or network-level vulnerability analysis. 2 Reopening time refers to the amount of time required to repair a bridge crossing to a state of repair sufficient to support the movement of emergency response vehicles; it is different from restoration time in that it does not refer to complete restoration to a pre-event state of repair.
} 
In February 2020, the RRAP research team met with ODOT bridge experts and other SMEs to review the BSST methodology and discuss potential improvements to the tool for its use in the Oregon Transportation Systems RRAP project. Following these initial and additional follow-up conversations, Argonne updated the BSST, including: increasing the resolution of projected damage due to seismicinduced forces by considering two bridge seismic design levels (operational and life-safety), and overhauling the approach for evaluating liquefaction damage. Appendix A provides further details on these major revisions as well as all other revisions implemented between the initial and current version of the BSST.

The RRAP team is grateful for the technical guidance, seismic design maps, bridge data, and review of analytic results provided by Ray Mabey, Albert Nako, and Corey Withroe from the ODOT Bridge Office; and also for critical feedback on technical and methodological aspects of the BSST provided by Professors Marc Eberhard (University of Washington), Peter Dusicka (Portland State University), Christopher Higgins (Oregon State University), Arash Khosravifar (Portland State University), Diane Moug (Portland State University), and Steve Kramer (University of Washington). The feedback and technical guidance provided by these individuals informed many of the enhancements to the BSST methodology discussed in this report.

The Oregon Department of Geology and Mineral Industries (DOGAMI) and ODOT provided significant hazard-related data and information, including earthquake seismic hazard design maps and tsunami inundation datasets.

\section{Identifying Relevant Hazards}

The goal of the BSST is to assess the projected damage to, and reopening time of, interstate, highway, and local bridges within the region following a CSZ earthquake. This assessment examined both the direct earthquake impacts (i.e., forces from seismic acceleration) and the impact of secondary earthquake-induced hazards on projected bridge damage and reopening times. Secondary earthquake-induced hazards assessed in this analysis include tsunamis and soil liquefaction.

Argonne initially considered for inclusion in the BSST several secondary earthquake-induced hazards, including slope instability (i.e., landslides), rock falls, and avalanches, but they were ultimately excluded because of inconsistent or unavailable data. Argonne also considered aftershocks for evaluation; however, estimating the degraded seismic capacity of bridges, damaged during an initial earthquake, to resist aftershocks is extremely uncertain, and the development of methods to do so requires extensive additional research. Furthermore, while aftershocks are characteristic of subduction zone earthquakes, predicting their timing and magnitudes are extremely uncertain, and as such, the current analysis excluded them (CREW 2013). The subsequent sections provide greater details on the direct and secondary earthquake-induced hazards included in the current version of the BSST, and a brief discussion of other earthquake-induced hazards not included in the current version of the BSST.

\section{CSZ Earthquake Ground Motion}

The CSZ is a subduction fault zone, where three regional tectonic plates (Explorer, Juan de Fuca, and Gorda) located just off the Pacific coast are subducting, or moving inland and sliding underneath the North American plate (CREW 2013). Across the globe, subduction faults have historically produced earthquakes of comparatively larger magnitude and longer duration than other, shallower fault types. The CSZ spans more than 1,000 kilometers from Northern California to Southern British Columbia and has the potential of producing a magnitude 9.0 (M9.0) or larger earthquake during a full-length fault rupture (USGS undated, PNSN undated). The recurrence frequency of such a full-length rupture of the CSZ fault is uncertain, with estimated recurrence rates between 350 and 600 years; however, 
some occurrences of such earthquakes have historically been separated by as few as 200 or as many as 1,000 years (CREW 2013). The date of the last known CSZ full-length fault rupture earthquake was in January 1700 (PNSN undated). Historical recurrence rates may suggest an increased risk of such an earthquake occurring in the near future. The Cascadia Region Earthquake Workgroup (CREW) estimates that a 10 percent probability exists of a full-length fault rupture occurring in the next 50 years (CREW 2013).

The development of the BSST used gridded shaking intensity values (PGA) that the U.S. Geological Survey (USGS) developed and published to determine projected PGA values for all bridges in Oregon (USGS 2017). The specific USGS scenario used in this analysis was the "M9.0 Scenario Earthquake - Cascadia M9.0 Scenario (mean value)." Stakeholders agreed upon this scenario and selected it to be consistent with CSZ earthquake scenarios used in previous research and planning activities conducted in Oregon and the Washington State Transportation Systems RRAP project (CISA 2019). Figure 1 shows projected PGA levels throughout Oregon from the USGS scenario.

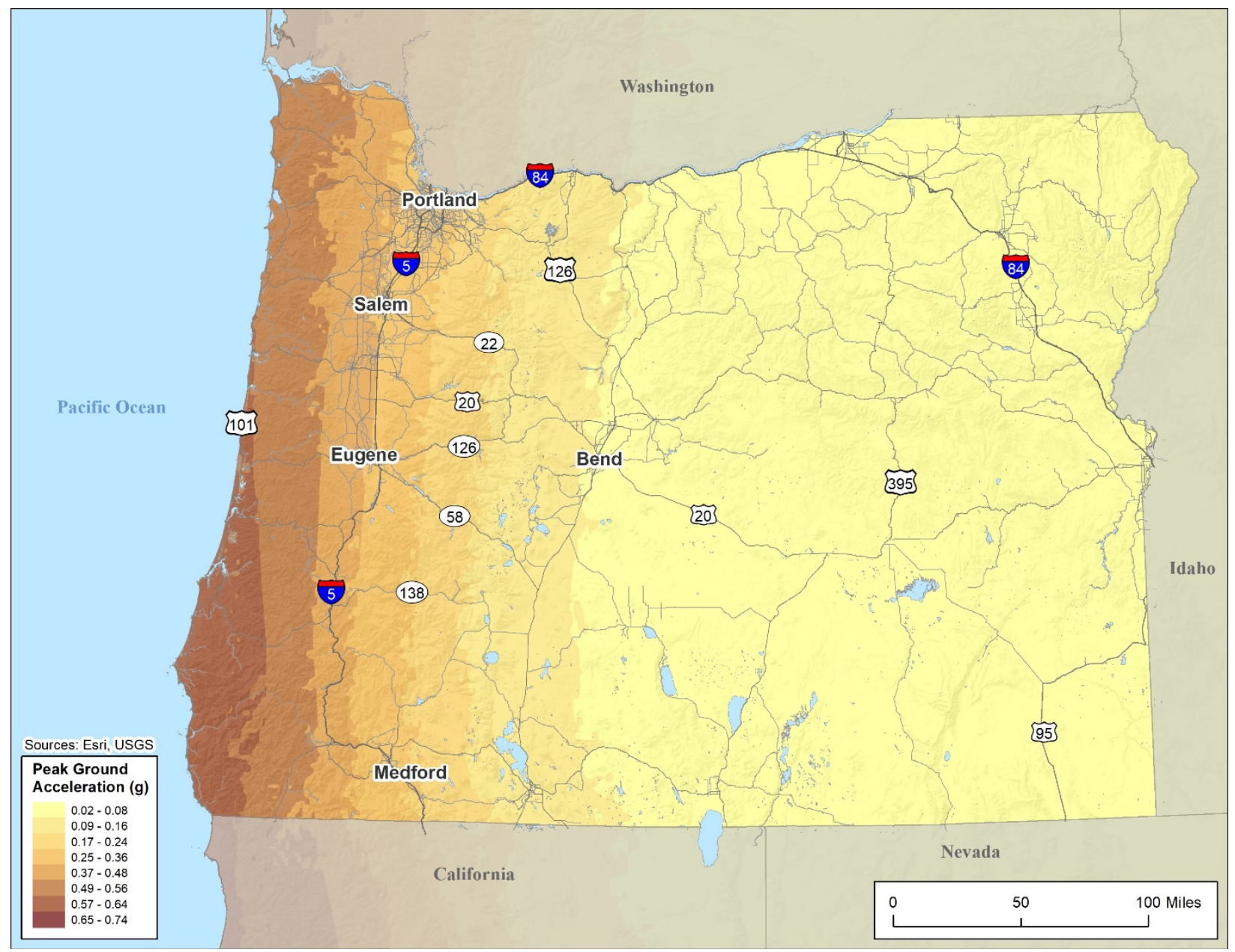

FIGURE 1.-Projected PGA for Oregon under the USGS M9.0 CSZ Scenario. ${ }^{3}$

${ }^{3} \mathrm{PGA}$ is expressed as an acceleration in units of $g, 1 \mathrm{~g}$ is the Earth's gravitational acceleration, or 9.81 meter per second squared $\left(\mathrm{m} / \mathrm{s}^{2}\right)$ 


\section{Tsunamis}

The sudden movement of tectonic plates beneath the ocean's surface during a CSZ earthquake has the potential to cause tsunamis. While the force of tsunami waves can damage bridge super- and substructures, other impacts can also occur. These include debris carried by tsunami waves accumulating against the bridge structure exerting significant lateral forces against the bridge piles and abutments, or water overtopping the bridge. Bridge overtopping can induce stresses into the bridge superstructure that can exceed its design strength and can potentially wash out the bridge deck.

Tsunamis can also cause rapid bridge scour, a condition where rapidly flowing water removes rocks, sediment, and other soils that support bridge foundations. When bridge scour removes significant quantities of sediment and rocks, bridge foundations can become exposed or potentially undermined, reducing the bearing capacity of the foundation. These conditions can significantly weaken vulnerable bridges and potentially cause partial or complete bridge collapse (WSDOT undated).

Within the bridge analysis methodology, bridge vulnerability to tsunami damage was determined using tsunami inundation data provided by the Oregon DOGAMI Open-File Reports. DOGAMI OpenFile Reports consist of reports, maps, data models, and user guides containing data or information, released quickly, and generally without comprehensive review. Figure 2 illustrates the tsunami inundation extents in Oregon. At the time of this study's bridge analysis, the most recent and appropriate modeled statewide tsunami inundation dataset was published in an Open File Report from 2013, version 0-13-19 (Priest et al. 2013). The report contains data models representing inundation as a result from CSZ earthquakes ranging in Slip Deficit, Maximum Slip, and Magnitude. For the purposes of this study, the most significant scenario-defined as 'XXL' 1,200-year (CSZ M9.1)-helped to assess damage to bridges. This tsunami scenario contains tsunami inundation extents and does not include inundation depth information.

The DOGAMI datasets project that most severe tsunami inundation in Oregon will occur primarily along the Pacific coast. However, some areas of the Columbia River and bays along the coastline may also experience tsunami inundation resulting from a CSZ earthquake. The Tsunami Damage section provides further details on the assessment of bridge vulnerability to tsunamis. 


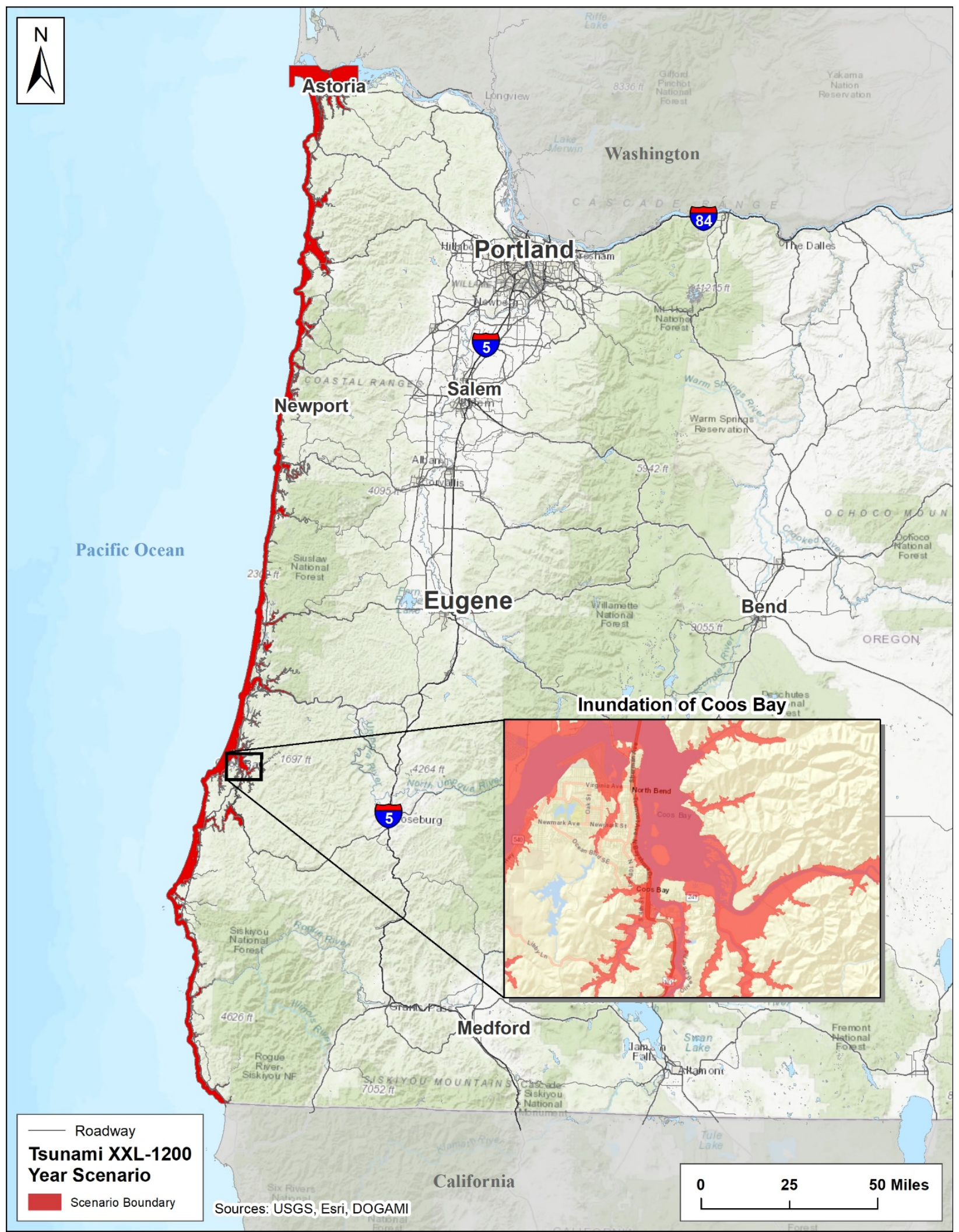

FIGURE 2.-Inundation Area of Oregon DOGAMI XXL 1,200-year Tsunami Scenario. 
Soil Liquefaction

During earthquakes, rapid changes in soil stresses can cause fundamental changes in soil mechanical properties that adversely affect the soil's load-bearing performance. One such change can occur in saturated, relatively loose (i.e., high void ratio), cohesionless soil when rapidly changing stress levels cause mean pore pressure to exceed the stress existing in the soil, which in turn causes the soil to lose nearly all strength and stiffness and begin behaving as a liquid rather than a solid. This phenomenon, known as liquefaction, poses a significant threat to bridge structures built upon soils with comparatively higher liquefaction potential. The Soil Liquefaction Damage section provides further details of how the BSST assesses bridges for liquefaction damage. 


\section{BSST Assessment Methodology}

The RRAP research team at Argonne initially developed the BSST methodology in coordination with WSDOT and subsequently updated the BSST methodology in coordination with ODOT. In its final form, the BSST assesses bridges for numerous types of vulnerabilities associated with seismic and seismic-related hazards following a full-length CSZ fault rupture. In this respect, the methodology evaluates bridges against a range of potential vulnerabilities, in many cases beyond those associated with the primary failure mode. For example, if a bridge is initially determined to have an inadequate structural design to resist seismic forces, the BSST will still evaluate additional potential vulnerabilities later in the assessment process to provide a more complete characterization of all possible failure modes. Conducting this additional analysis informs infrastructure resilience enhancement and investment decisions, and overall bridge repair or reopening times, all of which require identification of all bridge vulnerabilities. The developed methodology was implemented programmatically in Microsoft Excel using Visual Basic for Applications. The BSST also uses a bridge database that ODOT provided.

The BSST consists of three steps (figure 3). The first step of the methodology assesses the seismic design performance of a bridge by comparing the bridge's design capacity to the maximum PGA projected to occur at a bridge's location during a M9.0 full-length rupture of the CSZ (USGS 2017). The next step of the methodology evaluates potential bridge damage due to soil liquefaction and tsunami inundation. Finally, the methodology estimates bridge reopening times based on the projected extent and types of damage suffered by a bridge. The following sections provide greater details on each of these analytical steps.

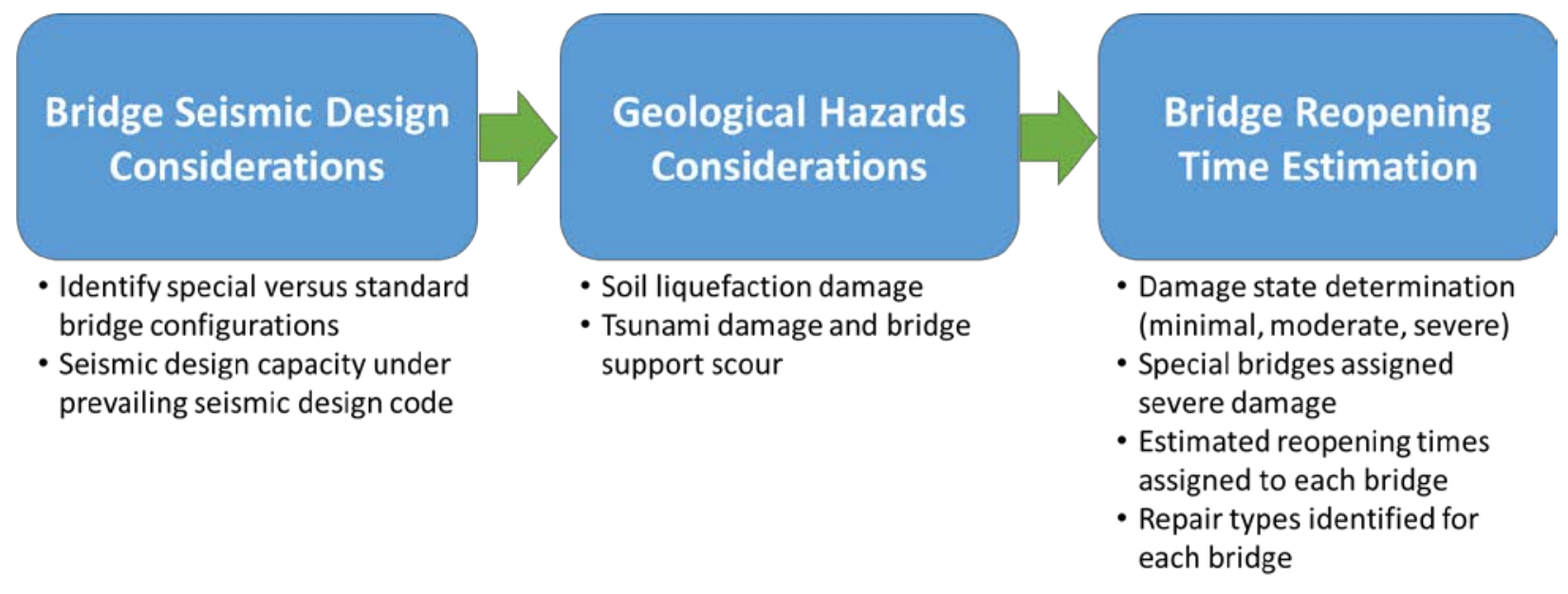

FIGURE 3.-BSST Methodology.

\section{Step 1: Bridge Seismic Design and Damage Potential}

The first step of the BSST analysis methodology focuses on bridge design to determine the type and extent of projected damage due to seismic loading following a full-length rupture of the CSZ fault. The primary types of damage include bridge failure due to bridge overloading (i.e., occurring when shaking during the CSZ full-length rupture exceeds a bridge's capability to withstand seismic shaking), soil liquefaction, and tsunami inundation damage.

The seismic design performance step begins by evaluating each bridge's design type, flagging it as either standard or special. The BSST methodology approximates damage on the basis of typical bridge performance for standard bridge designs. However, some bridges with non-standard designs (e.g., floating, suspension, moveable bridges) have unique vulnerabilities, and as such, the projected 
damage to these bridges is atypical. The following sections provide more details on the assessment of bridge damage types, starting with a discussion of how the BSST handles special bridge designs.

\section{Special Bridge Design Identification}

The seismic performance of special bridges is highly complex and thus requires detailed dynamic seismic structural analysis of the projected earthquake time series ground motion to determine projected bridge performance. Although the BSST evaluation of special bridge designs does not include evaluation of damage due to inadequate seismic design capacity, it does assess such bridges for other potential vulnerabilities, including liquefaction and tsunami-related overtopping or scour.

The BSST considers five bridge type classifications as special bridges: moveable, floating, cablestayed, suspension, and steel-tied arch. Of the 5,646 open roadway bridges in Oregon evaluated during the 2018 Oregon Transportation Systems RRAP project, 23 bridges are special bridges ( 3 suspension and 20 movable bridges). Within the BSST, analysts provide reopening times for all special bridges as an input; based on discussions with ODOT, Argonne assumed all special bridges in Oregon sustained severe damage with a reopening time of 2.5 years.

The BSST also gives special consideration to bridges with hollow core concrete pile supports, which are highly vulnerable to earthquake damage and have very limited capability to withstand seismic forces. While these bridges may have a more standard design configuration, the unique seismic concerns associated with hollow-core piles nonetheless warrant special consideration, and they are therefore designated as special bridges in the BSST methodology. No feasible method for seismically retrofitting such piles has been identified. As such, bridges with hollow core concrete piles are assumed to suffer severe damage regardless of the PGA they experience during the M9.0 CSZ fulllength rupture earthquake scenario. The BSST still assess bridges with hollow core concrete columns for other potential damage, such as soil liquefaction and tsunami damage, determines the reopening time for these bridges. The Oregon bridge database contained insufficient information to identify bridges with hollow core concrete pile supports, and as such, the study assumes that no Oregon bridges had hollow core concrete pile supports.

Finally, ODOT bridge engineers recommended giving special consideration for bridges with precast concrete piles as these are more vulnerable to seismic induced damages. As such, the BSST assumes that any bridge (regardless of the prevailing design code in the year of bridge construction) with precast concrete piles experiences severe damage when exposed to a PGA seismic hazard exceeding $0.1 \mathrm{~g}$.

\section{Bridge Seismic Design Considerations}

For all other bridges with standard design configurations (i.e., not special bridges), projecting bridge performance during an earthquake begins with determining each bridge's seismic design capacity. Without performing detailed dynamic seismic analysis, the exact seismic capacity of bridges cannot be determined. However, bridge seismic capacity can be approximated by considering the seismic design code that governed at the time when engineers designed the bridge. For the analysis of bridges in Oregon, seismic design capacity of all bridges (i.e., interstate, highway, and local bridges) was based on ODOT's historical seismic design of highway bridges.

Bridge seismic design in Oregon began in 1958 (ODOT 2009), and therefore any bridges in Oregon designed prior to 1958 were not designed with consideration of seismic forces, although some may have some inherent capability to withstand seismic forces. From 1958-1974, bridges were designed to withstand a seismic force of 0.02g to 0.06g (ODOT 2009). Following the adoption of the Interim Specifications by the American Association of State Highway and Transportation Officials (AASHTO) 
Bridges in 1975, bridges in Oregon were designed using the Interim Specification from 1975 to 1990. In 1990, ODOT developed an interim Seismic Specifications Hazard Map for the state and used this to design bridges from 1991 to 1995 . Following the development of a 500-year recurrence rate hazard map for the state by an earthquake engineering consultant firm, ODOT used this map to design bridges from 1995-2003 (ODOT 2009).

In 2004, ODOT began designing bridges considering two design levels: operational and life-safety. The operational design level corresponds to a hazard level up to which bridges are expected to experience minor damage and thus remain operational, while the life-safety design level corresponds to a hazard level up to which bridges have a very low probability of collapse (ODOT 2009). From 2005 to 2016, ODOT used the 2002 USGS 500-year recurrence rate hazard map for the operational design level and the 2002 USGS 1,000-year recurrence rate hazard map for the life-safety design level. Finally, in October 2016, ODOT adopted the 2014 USGS 1,000-year recurrence rate hazard map for life-safety design level and seismic hazard maps for a full-length CSZ earthquake for the operational design level. Given that highway bridges built in Oregon since 2017 have been designed to be minimally damaged during a full-length CSZ earthquake, Argonne assumed bridges built since 2017 would not sustain any significant damage due to seismic loading during the CSZ scenario earthquake and thus the bridges are not explicitly assessed in the BSST. However, the BSST did assess these bridges for potential liquefaction or tsunami damages.

Based on discussions with WSDOT during the initial BSST development, the initial BSST implementation assumed that all bridges had an inherent seismic capacity of $0.15 \mathrm{~g}$. During the 2018 Oregon Transportation Systems RRAP project, this assumption was revised based on conversations with bridge engineering SMEs. Bridges in Oregon built in 1976 or later were designed with seismic detailing, and thus Argonne assumed these bridges have an inherent seismic capacity of $0.2 \mathrm{~g}$, corresponding to an operational design level. Argonne assumed the seismic capacity of bridges built before 1976 based on seismic fragility curves, developed in Bazáez Gallardo (2017), for bridges subjected to long duration strong ground motion during subduction megathrust earthquakes (Bazáez Gallardo 2017).4 Specifically, the BSST adopted fragility curves for the 'Moderate' and 'Collapse' damage states for RC bridge bents to represent operational and life-safety design levels, respectively, for bridges built before 1976. Argonne estimated deterministic seismic capacities ( $0.17 \mathrm{~g}$ and $0.35 \mathrm{~g}$ for the operational and life-safety design levels, respectively) from these fragility curves corresponding to a PGA at which a bridge has a 20 percent probability of experiencing at least moderate or collapse damage levels.

Given that bridges designed before 2004 were constructed considering a single seismic hazard level, Argonne assumed the seismic hazard level (PGA) used to design bridges before 2004 corresponded to an operational design level. Furthermore, based on recommendations from bridge engineering SMEs, Argonne scaled the seismic hazard design level (PGA) used to design bridges designed before 2004 by a factor of 1.4 to approximate a life-safety design level. The BSST operationalizes this logic for bridges designed between 1975 and 2003 by determining the maximum between the design PGA (specified in the prevailing design code when engineers designed a bridge, assumed to be 1 year before year built) and the assumed inherent seismic capacity $(0.2 \mathrm{~g})$, and then multiplying this value by 1.4 . Similarly, the BSST determines the life-safety design capacity for bridges design between 2004 and 2015 as the maximum between the 1,000-year seismic hazard design value and the product of 1.4 and the inherent seismic capacity $(0.2 \mathrm{~g})$.

The BSST determines the design year of a bridge as one year before the more recent date between (1) the year the bridge was constructed and (2) the year during which a bridge underwent seismic

\footnotetext{
${ }^{4}$ Fragility curves provide the probability of a structure experiencing a defined level of damage or a more severe level of damage as a function of hazard severity (e.g., PGA for a seismic fragility curve).
} 
retrofit as identified by ODOT. Table 1 provides the documents and/or methods used for determining bridge seismic design capacity on the basis of bridge design (or seismic retrofit) year.

TABLE 1.-Determination of Oregon Bridge Seismic Design Capacity Based on Bridge Design Year.

\begin{tabular}{|l|l|l|}
\hline $\begin{array}{l}\text { Bridge } \\
\text { Design Year }\end{array}$ & $\begin{array}{l}\text { Operation Design (Moderate Damage } \\
\text { PGA Threshold) }\end{array}$ & $\begin{array}{l}\text { Life-Safety Design (Severe Damage } \\
\text { PGA Threshold) }\end{array}$ \\
\hline Before 1975 & $0.17 \mathrm{~g}$ & 0.35g \\
\hline $1975-1990$ & max (AASHTO Interim Specifications, 0.2g) & $\begin{array}{l}1.4 * \text { max (AASHTO Interim Specifications, } \\
0.2 \mathrm{~g})\end{array}$ \\
\hline $1991-1994$ & max (1991 seismic hazard, 0.2g) & $1.4 * \max (1991$ seismic hazard, 0.2g) \\
\hline $1995-2003$ & max (1995 seismic hazard, 0.2g) & $1.4 *$ max (1995 seismic hazard, 0.2g) \\
\hline $2004-2015$ & max (500-year seismic hazard, 0.2g) & max (1,000-year seismic hazard, 1.4*0.2g) \\
\hline 2016 or later & $\begin{array}{l}\text { Bridges built in 2017 or later were designed } \\
\text { using full-length rupture CSZ earthquake } \\
\text { PGA hazard values for operational design } \\
\text { level. }\end{array}$ & $\begin{array}{l}\text { Bridges built in 2017 or later were designed } \\
\text { year PGA hazard level for life-safety design } \\
\text { level. }\end{array}$ \\
\hline
\end{tabular}

For bridges designed between 1975 and 2015, the Argonne team digitized the PGA contour maps in the prevailing design codes using ESRI ArcGIS software and then overlaid this digitized PGA map with bridge locations to determine the PGA levels that would have been used in their design. If a bridge fell between contour lines, then the bridge was assigned the more conservative of the two contour values.

After determining a bridge's operational and life-safety seismic design capacities, those design capacities are compared to the projected PGA at the bridge from the M9.0 CSZ scenario to determine projected bridge performance. If the projected PGA value from the M9.0 CSZ scenario exceeds the bridge's life-safety seismic capacity, the bridge is assumed to sustain severe damage. If the projected PGA value from the M9.0 CSZ scenario exceeds the bridge's operational seismic capacity but is less than the bridge's life-safety capacity, the bridge is assumed to sustain moderate damage. WSDOT and ODOT bridge engineers noted that bridges with single spans (i.e., no columns) or bridges with pier walls tend to prove more resilient to seismic loading and sustain less damage than other bridge configurations when overloaded. As such, bridges with single-span or pier wall support designs that are projected to experience a PGA exceeding the bridge life-safety design capacity were considered to be moderately damaged because of excessive seismic loading. Likewise, bridges with single-span or pier wall support designs that are projected to experience a PGA exceeding the bridge operational design capacity were considered to experience minimal damage because of excessive seismic loading.

\section{Step 2: Geological Hazard Considerations}

In addition to evaluating the damage caused by direct seismic forces exceeding bridge design capacities, the BSST assesses damage caused by two other seismic-related geological hazards: soil liquefaction and tsunami-related inundation and bridge scour hazards.

\section{Soil Liquefaction Damage}

The initial BSST implementation in Washington evaluated potential bridge damage due to soil liquefaction during the CSZ seismic scenario by assuming a deterministic PGA threshold (0.1g to $0.15 \mathrm{~g})$ for liquefaction based on liquefaction potential data provided by Washington State Department of Natural Resources. In this original implementation, the BSST assumed a bridge 
located on soils vulnerable to liquefaction experienced severe damage if exposed to a seismic hazard value exceeding the PGA liquefaction threshold.

During the 2018 Oregon Transportation Systems RRAP project, Argonne substantially revised the evaluation of soil liquefaction based on feedback from bridge engineering SMEs, which indicated that the methodology for evaluating soil liquefaction was overly conservative. The first major change was increasing the granularity of the damage assessment to include consideration of two potential levels of damage. The second major change was evaluating potential liquefaction damage based on the projected peak ground displacement (PGD) at bridge locations rather than projected PGA. To implement these changes, Argonne adopted bridge seismic fragility curves for lateral spreading developed in Brandenberg et al. (2011). Within this reference, bridge seismic fragility curves are established for six prototypical bridge designs for slight, moderate, extensive and collapse damage levels. The Argonne team adopted the fragility curves for the moderate and collapse damage levels, combining the six median values for each damage state as a geometric mean. The BSST uses these geometric mean values $(0.14 \mathrm{~m}$ for moderate damage state and $0.2 \mathrm{~m}$ for collapse damage state) as deterministic PGD thresholds for liquefaction damage.

For the analysis of bridges in Oregon, the Argonne team computed PGD associated with the CSZ scenario earthquake at each bridge location. If the PGD at a bridge location exceeds the geometric mean of the six median PGD values for the collapse damage state, the BSST assumes the bridge experiences severe damage due to liquefaction. Similarly, if the PGD at a bridge location exceeds the geometric mean of the six median PGD values for the moderate damage state (computed as $0.14 \mathrm{~m}$ ) but is less than the geometric mean of the six median PGD values for the collapse damage state, the BSST assumes the bridge experiences moderate damage due to liquefaction.

\section{Tsunami Damage}

Next, the BSST assesses bridges for damage caused by tsunami impacts, which can include bridge scour or overtopping of bridge decks leading to excessive lateral loads on the bridge structure. The tool assessed bridges for both of these tsunami damage types within the bridge analysis methodology. As previously mentioned, Oregon DOGAMI Open-File Reports provided tsunami inundation maps.

Bridge vulnerability to tsunamis is determined by comparing bridge geolocation to the tsunami inundation map for the 'XXL' 1,200-year (CSZ M9.1) scenario. If a bridge lies within the mapped tsunami inundation zone, the BSST considers the bridge vulnerable to tsunami inundation. At the time of this study, available tsunami inundation data did not include inundation depth information. As such, bridge overtopping during a tsunami could not be directly assessed. Instead, the waterway adequacy code in the ODOT bridge database is used as a proxy for bridge vulnerability to overtopping. The waterway adequacy code is based on the historical frequency of bridge overtopping due to flooding. The BSST assumes that any bridge located in a tsunami inundation area experiences severe damage due to tsunami overtopping if it either has an unknown waterway adequacy code or a National Bridge Inventory waterway adequacy code identifying "Occasional overtopping of bridge deck and roadway approaches with significant traffic delays," or more severe or frequent overtopping.

Next, the BSST assesses bridges for potential scour damage using the bridge scour rating in the ODOT bridge database. The tool assumes any bridge located in the tsunami inundation zone that is listed as scour critical experiences severe damage due to scour during a CSZ-related tsunami. 
Step 3: Bridge Reopening Times

All bridge vulnerability and potential-damage analyses are ultimately used to inform the determination of an approximate bridge reopening time for each structure following a full-length rupture of the CSZ fault. Bridge reopening time is different from bridge repair time or restoration time; reopening time refers to the amount of time required to repair a bridge crossing to a minimum functional state of repair sufficient to support the movement of emergency response vehicles. It does not necessarily refer to complete restoration to a pre-event state of repair. The estimated reopening times include the time necessary to perform a bridge damage inspection, bridge rehabilitation or bridge replacement, or to construct a temporary road to bypass the bridge. Argonne determined bridge reopening times (table 2) in collaboration with WSDOT bridge engineers during the initial BSST development and slightly modified these times following discussions with ODOT bridge engineers on the basis of damage criteria, bridge length, and repair type, as discussed in the following sections.

- No Bridge Damage - The BSST assumes bridges identified as suffering neither severe nor moderate damage sustain no structural damage during the CSZ earthquake scenario and thus do not require any repairs prior to reopening. These bridges may suffer minor surface cracking.

- Moderate Bridge Damage - For bridges projected to suffer moderate damage from at least one damage type and not identified as suffering severe damage of any of the potential damage types, the BSST assumes these bridges to be moderately damaged following the CSZ earthquake scenario and related geological hazards. For such bridges, it is assumed that a bridge damage inspection would be necessary prior to reopening, but that limited or no bridge repairs would be required. Furthermore, it is assumed that the bridge inspection and any necessary repairs would require 4 days to complete, after which time the bridge would be reopened.

- Severe Bridge Damage - Bridges identified as suffering severe damage are evaluated within the BSST to determine the amount of time required to either repair or replace the bridge, or to build a temporary road that bypasses the bridge, if possible. Bridges suffering severe damage are considered damaged to such an extent that major bridge rehabilitation, partial rebuild, or complete rebuild would be necessary. Given the extensive time required for such work, the construction of temporary roadways to replace bridges when possible was deemed preferential in the BSST methodology. If it was determined that a temporary roadway could not be constructed, the bridge rehabilitation or replacement time was determined as a function of bridge length and considerations of any subsurface strengthening necessary to improve liquefied soils at the bridge location. 
TABLE 2.-Bridge Reopening Times and Repair Types Based on Damage and Bridge Length.

\begin{tabular}{|c|c|c|c|c|c|}
\hline $\begin{array}{l}\text { Damage } \\
\text { Level }\end{array}$ & Damage Type & Consideration & $\begin{array}{l}\text { Bridge } \\
\text { Length in } \\
\text { Feet (ft.) }\end{array}$ & Reopening Time & Repair Type \\
\hline None & None & None & $\mathrm{N} / \mathrm{A}$ & 0 days & None \\
\hline Moderate & Minor or None & None & N/A & 4 days & $\begin{array}{l}\text { Bridge inspection and } \\
\text { minor or no repairs }\end{array}$ \\
\hline \multirow[t]{8}{*}{ Severe } & \multirow[t]{2}{*}{$\begin{array}{l}\text { Any severe } \\
\text { damage type }\end{array}$} & \multirow{2}{*}{$\begin{array}{l}\text { Bridge not over } \\
\text { waterway or } \\
\text { impassable } \\
\text { topography } 5\end{array}$} & $>50$ & $\begin{array}{l}2 \text { weeks per } 50 \\
\mathrm{ft} . \text { of bridge } \\
\text { length }\end{array}$ & \multirow[t]{2}{*}{ Temporary road } \\
\hline & & & $\leq 50$ & 2 weeks & \\
\hline & \multirow{3}{*}{$\begin{array}{l}\text { Severe damage } \\
\text { without soil } \\
\text { liquefaction }\end{array}$} & \multirow{3}{*}{$\begin{array}{l}\text { Bridge over } \\
\text { waterway or } \\
\text { impassable } \\
\text { topography }\end{array}$} & $>150$ & 2 years & \multirow{3}{*}{$\begin{array}{l}\text { Major bridge } \\
\text { rehabilitation or } \\
\text { replacement }\end{array}$} \\
\hline & & & $\leq 150,>50$ & 14 months & \\
\hline & & & $\leq 50$ & 7 months & \\
\hline & \multirow{3}{*}{$\begin{array}{l}\text { Severe damage } \\
\text { with soil } \\
\text { liquefaction }\end{array}$} & \multirow{3}{*}{$\begin{array}{l}\text { Bridge over } \\
\text { waterway or } \\
\text { impassable } \\
\text { topography }\end{array}$} & $>150$ & 2.5 years & \multirow{3}{*}{$\begin{array}{l}\text { Major bridge } \\
\text { rehabilitation or } \\
\text { replacement and } \\
\text { subsurface strengthening }\end{array}$} \\
\hline & & & $\leq 150,>50$ & 1.5 years & \\
\hline & & & $\leq 50$ & 8 months & \\
\hline
\end{tabular}

\section{Temporary Road Considerations}

The BSST considers temporary bypass roads to be a viable option for damaged bridges that do not cross waterways and where the underlying topography is relatively flat; that is, the bridge does not traverse a deep ravine or other impassable topographic feature. The tool uses the waterway adequacy code in the ODOT bridge database to determine whether a bridge crosses a waterway. A digital elevation model (DEM) of Oregon published by the Oregon Geospatial Enterprise Office is used to identify large variations in ground elevation below a bridge structure (Oregon Spatial Data Library 2016). ${ }^{6}$ This is done by determining the maximum and minimum ground elevations that occur beneath the entire length of each bridge and computing the total change. If the calculated difference between the maximum and minimum ground elevations below a bridge exceeds $30 \mathrm{ft}$., the BSST assumes that variations in land topography are too great to feasibly construct a temporary surface roadway to bypass the bridge. If the difference between the maximum and minimum ground elevations is less than or equal to $30 \mathrm{ft}$., the BSST assumes that a temporary surface roadway is a viable bypass option.

For the analysis of bridges in Oregon, identifying the ground elevation under a bridge involved a twostep process. The first step involved merging the bridge database with a roadway database, and then developing a linear feature representation of each bridge by assuming the point feature of each bridge in the ODOT bridge database was located at the centerline of the bridge structure. The second step involved using a spatial join of the bridge points and the DEM dataset to capture the maximum and minimum ground elevation for each bridge. This was achieved by using the ArcGIS Spatial Statistics 3D Analyst toolbox (Esri, undated).

When the tool determined that a temporary road can be built to bypass a severely damaged bridge, the time necessary to construct the temporary road is computed as a function of bridge length. For bridges up to $50 \mathrm{ft}$. in length, a value of 2 weeks is used to approximate bypass road construction

\footnotetext{
5 See Temporary Road Considerations section for definition of impassable topography.

6 The DEM provides ground elevation; a 10m DEM resolution was used in this analysis.
} 
time. For bridges over $50 \mathrm{ft}$. in length, a value of 2 weeks per $50 \mathrm{ft}$. of bridge length is used. These construction estimates are based on conversations with WSDOT personnel during the initial BSST development. It is important to note that these roadway construction time estimates are based on the construction of roads with a temporary wearing surface (e.g., compacted gravel) to enable the passage of emergency response and recovery vehicles. These temporary roadways are not intended for public use, would not be as durable as roadways with more permanent wearing surfaces, and would likely require ongoing maintenance given heavy use by emergency response and recovery vehicles and environmental conditions.

\section{Bridge Rehabilitation or Replacement}

When the construction of a temporary road is not feasible, bridge rehabilitation or replacement is necessary. On the basis of discussions with WSDOT bridge engineers during initial BSST development, bridge length and the potential need for soil liquefaction mitigation improvements were identified as the primary metrics influencing bridge repair or replacement time. The bridge replacement times are provided in table 2 . Generally, bridges that are greater in length and requiring soil liquefaction mitigation require longer reopening times than those with shorter spans or no soil liquefaction.

\section{Discussion of Analytical Uncertainty}

Argonne developed the BSST analytical methodology in close collaboration with WSDOT bridge engineers and updated the BSST in close collaboration with ODOT bridge engineers and bridge engineering SMEs, with agreement that this analysis likely represents a "worst case scenario" for bridge damage due to an M9.0 CSZ earthquake scenario. Several assumptions that affect the uncertainty in the bridge analysis have been described throughout this report. However, several additional overarching sources of uncertainty in the bridge analysis are important to note, yet are difficult to quantify and account for systematically in the BSST. For this reason, the following section broadly covers several additional sources of uncertainty that could influence the outcomes of the BSST analysis.

\section{Bridge Data Uncertainty}

Several datasets were identified and used for the bridge analysis, including the following:

- ODOT Bridge Inventory Database

- Oregon Geospatial Enterprise Office 10m Digital Elevation Model

- Oregon DOGAMI Open-File Reports for Tsunami Inundation Area Maps

Many of these datasets were highly structured and standardized; however, as with any dataset, errors may be present, and data may be incomplete. The current analysis assumes that all datasets are accurate to the extent possible. The researchers identified some errors during the course of the analysis, which they strove to address. However, it is possible that some errors remain in the source data that could contribute to uncertainty or errors in the overall analysis.

\section{Bridge Performance Uncertainty}

It is impossible to predict with certainty how a given bridge will perform. Even a full dynamic structural analysis, which requires significant labor and costs beyond the scope of this project, can only seek to minimize uncertainty. Argonne made the assumptions listed below regarding the influence of various bridge properties on the projected bridge vulnerability and performance. 


\section{Seismic Design Capacity}

Determining bridge seismic design capacities is a two-stage process: the first stage determines the bridge design year and the second estimates operational and life-safety bridge seismic design levels based on bridge design year. Uncertainties exist in estimating the bridge seismic design capacity on the basis of the bridge seismic design year and design values provided from several sources, or assumed values for bridges built prior to the first seismic design of bridges in Oregon in 1975 (ODOT 2009; Bazáez Gallardo 2017). A major assumption of this analysis is that the seismic design hazard maps used by ODOT for designing bridges over time are representative of the hazard maps considered in the design of all bridges in the state.

Bridge seismic design hazard maps helped determine seismic design capacities for bridges with design years between 1975 and 2015, by evaluating PGA maps and choosing the lesser of the two bounding PGA map contours. This method assigns a conservative seismic design value where seismic capacity is less than the projected PGA for the design, and it assumes that bridges are designed only to withstand the minimum PGA as required by code. Some bridges may have been designed to a seismic capacity greater than that mandated in the prevailing design code. Both of these factors potentially underestimate seismic design capacity for bridges with design year between 1975 and 2015.

Bridges in Oregon designed before AASHTO's adoption of the Interim Specifications in 1975 are not seismically designed, and they are assumed to have operational and life-safety seismic design capacities based on seismic fragility curves developed in Bazáez Gallardo (2017) for standard RC bridge bents exposed to long duration strong ground motions.

\section{Projected Seismic Damage}

The BSST methodology assumes a bridge suffers severe damage when the PGA from the CSZ scenario earthquake exceeds the bridge's life-safety seismic design capacity or it suffers moderate damage when the PGA from the CSZ scenario earthquake exceeds the bridge's operational seismic design capacity but is less than the bridge's life-safety seismic design capacity. In reality, some bridges will likely experience moderate or severe damage when exposed to PGA below the operational or life-safety seismic design levels, respectively, while other bridges will suffer damage when exposed to PGA less than the seismic design levels.

\section{Bridge Skew}

The BSST methodology does not account for bridge skew, which is the angle between the bridge roadway centerline and the centerline of the bridge supports (i.e., pier or abutment). Bridges with significant skew angles perform differently than bridges with small or no skew angles, and the AASHTO seismic bridge design codes did not account for bridge skew effects until 2007 (Fu and Chun 2013).

\section{Pier Wall and Single Span}

The BSST methodology assumes that bridges are damaged if the PGA experienced exceeds their capacity levels. However, WSDOT bridge engineers indicated that bridges with either a single span (no columns) or pier wall supports may perform better than expected. As such, bridges with either pier walls or single spans are projected to suffer a lower level of damage when exposed to PGA exceeding their design levels.

\section{Bridge and Span Length}

The effects of total bridge structure length and maximum span length on projected bridge damage were not considered; however, total bridge length was a primary driver of projected bridge reopening time. 


\section{Fracture Critical Bridges}

Some bridges have fracture-critical members, where lack of redundancies in the primary structural members could cause partial or complete bridge collapse or a significant degradation in a bridge's structural capacity (FHWA 2012). Discussions with WSDOT bridge engineers suggested that fracturecritical bridges may not be any more vulnerable to seismic damage than non-fracture-critical bridges. Therefore, the BSST makes no special consideration for such bridges.

\section{Hazard Uncertainties}

The bridge analysis methodology considered several hazards, but the bridge analysis methodology excluded some additional hazards, owing to excessive uncertainties, complexities in modeling such hazards, or minimal anticipated impact to bridges. The following sections detail the various assumptions and sources of uncertainties in the hazards considered in or excluded from this analysis.

\section{Scenario Earthquake}

The USGS M9.0 full-length CSZ rupture earthquake scenario was selected for the Oregon Transportation Systems RRAP project analysis to remain consistent with the Federal Emergency Management Agency, WEMD, WSDOT, and ODOT planning efforts to date, as well as to align with the hazard considered in the 2017 Washington State Transportation Systems RRAP. The projected ground motion values are a function of several complex phenomena and properties including ground attenuation, fault location and geometry, faulting and stress release along the fault, and location of earthquake initiation along the fault. These characteristics inform a fault's theoretical maximum earthquake and also help to estimate the probability of occurrence of earthquakes of various intensities, communicated as a rate of recurrence. Given uncertainty in these estimations, the frequency of a full-length rupture of the CSZ fault is uncertain, with estimated recurrence rates between 350 and 600 years; however, occurrences of such earthquakes have historically been separated by 200-1,000 years (CREW 2013).

USGS has published several CSZ scenario earthquakes based on different assumptions in model parameters. As stated previously, this analysis used the M9.0 full-length CSZ rupture earthquake scenario to be consistent with prior research and planning efforts in CISA Region 10.

\section{Soil Liquefaction}

Liquefaction is a highly uncertain phenomenon that is a function of soil void space, water saturation (which can be seasonally dependent), and other factors. Argonne assumed critical PGA thresholds that could initiate liquefaction in vulnerable soils based on bridge seismic fragility curves for lateral spreading developed in Brandenberg et al. (2011). As such, it is likely that some bridges currently projected to experience liquefaction damage may not suffer any liquefaction damage during a CSZ event, while others not currently projected to experience liquefaction damage may suffer liquefaction damage during a CSZ event.

\section{Tsunami Uncertainty}

Significant uncertainties exist in the projected extent of bridge damage due to tsunamis caused by a full-length rupture of the CSZ fault: in the projected extent of inundation, the severity and depth of inundation, and the level of damaged caused.

The tsunami inundation map for the 'XXL' 1,200-year (CSZ M9.1) scenario from Oregon DOGAMI Open-File Reports did not contain information on the projected inundation depth. Incorporating that information into this study in the future could affect the outcomes for bridges in coastal locations related to overtopping and increased scour potential. 
One of the primary ways in which bridges suffer damage during a tsunami is from bridge overtopping. As inundation depth information was not available at the time of analysis, the BSST methodology uses the National Bridge Inventory waterway adequacy code as a proxy for bridge vulnerability to tsunami overtopping based on historical rates of bridge overtopping (FHWA 2018). It is unclear whether this assumption may cause an over- or under-estimation of potential overtopping damage during a CSZ tsunami.

Tsunami waves can also cause new, or exacerbate existing, bridge scour. Predicting the likelihood and severity of scour that tsunamis cause with greater certainty would require a bridge-by-bridge analysis, which is outside the scope of this study. Only 16 percent of bridges within Oregon are scourcritical bridges, and only 51 of these bridges are located within a tsunami inundation area.

The collection of debris carried by tsunami waves against bridge abutments and piers can contribute significantly to bridge damage; however, this is an extremely uncertain and difficult-to-model phenomenon that is affected by numerous external factors. In the BSST, the risk of debris-damming was not explicitly considered, but the use of the bridge waterway adequacy code as correlating with an increased risk of tsunami damage may offer some indirect consideration of debris accumulation impacts.

\section{Excluded Geologic Hazards}

The BSST excludes several geological hazards from the bridge analysis methodology, including landslides, rock slides, avalanches, ground faulting and lateral spread, and aftershocks. The analysis did not include these hazards because of uncertainties such as lack of available data, lack of available models, or complexity of models which precluded their use in the bridge analysis methodology; uncertainties in bridge vulnerability to these hazards; or uncertainty in the dependency and correlation between these hazards and hazards considered in the bridge analysis methodology. Inclusion of these hazards would likely increase the projected bridge damage and reopening times that the bridge analysis methodology projects; however, it is unclear to what extent this inclusion would impact the results.

Utilities Carried by or Located Near Bridge

Utilities, often collocated on bridges, can affect both bridge vulnerability and reopening time, as damage sustained by the utilities themselves can affect the bridge structure. This analysis did not consider the potential for damage to these systems to cause damage to bridges.

\section{Dam Failure}

Stakeholders in Oregon expressed concern that dam failure as the result of an earthquake could affect bridges. Indeed, dam failures have the potential to create flood waves or inundation areas that could damage bridges located within the proximate risk area. Dam vulnerability to failure during an earthquake was outside of the scope of this analysis; therefore the BSST methodology did not consider flooding or flood wave impacts on bridges as a result of local dam failures.

\section{Repair Type and Reopening Time}

Bridge repair types and reopening times are determined using the projected levels and types of damage determined by the BSST methodology. Argonne assumed repair types and reopening timelines on the basis of discussions with WSDOT and ODOT bridge engineers; however, uncertainty exists in these assumptions, as outlined in the following sections. 
Temporary Roadways

Bridges projected by the BSST to sustain severe damage are evaluated for the viability of a new, temporary bypass roadway (e.g., around a collapsed overpass). The BSST assumes that severely damaged bridges over waterways or large elevation changes, such as ravines or canyons, cannot be replaced by a temporary bypass, but that all others could be temporarily bypassed. The methodology assumes large elevation changes in excess of $30 \mathrm{ft}$. prohibit bypasses.

Route Service Restoration Time Uncertainty

Discussions with WSDOT and ODOT bridge engineers informed assumed bridge repair and replacement, bridge structural inspection, and temporary roadway construction times. The estimated times were based on several assumptions about the availability of repair crews, construction materials, and equipment, as well as the ability of these to access a bridge site, as discussed in the following paragraphs.

The assumed bridge repair and replacement, bridge structural inspection, and temporary roadway construction times were based on the assumption of an unconstrained workforce and excluding potential funding or permitting delays.

Within the bridge analysis methodology, the ability to access a site was not considered. Thus, the projected bridge reopening times are independent of any potential delays in accessing a bridge location to commence repair work.

The reopening-time assumptions in the bridge analysis methodology assume the general and unconstrained availability of construction materials and equipment through a coordinated national emergency response effort. 


\section{Bridge Seismic Screening Results}

Analysts assessed 5,646 open roadway bridges incorporated into this study from the ODOT bridge inventory database using the BSST analysis methodology detailed previously in this report. Results consist of three types of outcomes: Bridge Damage Levels and Types, Bridge Repair Types, and Bridge Reopening Times.

\section{Bridge Damage Levels and Types}

As discussed in previous sections of this document, the BSST projects the level of damage (None, Moderate, Severe) expected for three bridge damage types (i.e., shaking, liquefaction, and tsunami damages). Direct damage due to shaking during an earthquake is not assessed for bridges of special design. These results for the CSZ scenario earthquake are summarized in table 3 . While a large number of bridges evaluated are projected to experience no damage (1,335 bridges), ${ }^{74,288}$ bridges ( 76 percent of assessed bridges) are projected to experience some level of damage, with 2,012 bridges (35.6 percent) projected to experience moderate damage and 2,276 bridges (40.3 percent) projected to experience severe damage. Of the 23 special design bridges evaluated for potential liquefaction and tsunami damage, 8 are projected to experience major liquefaction, and 1 is projected to experience minor liquefaction. Furthermore, while 11 of the special design bridges fall within tsunami inundation zones, none is project to experience overtopping or scour damage due to tsunami waves.

Direct damage caused by ground motion during the CSZ scenario earthquake is the largest driver of severe and moderate damage in Oregon, inducing (either exclusively or as a contributing hazard) severe damage in 1,692 bridges (30.0 percent) and moderate damage in 1,991 bridges (35.3 percent). Liquefaction is the second greatest contributor to bridge damage in Oregon, directly causing or contributing to severe damage in 989 bridges (17.5 percent) and moderate damage in 190 bridges (3.4 percent), respectively. Tsunami-induced damages (i.e., severe scour and overtopping) are limited. Only 301 bridges (5.3 percent of open roadway bridges) are located in tsunami inundation areas; tsunami waves are projected to induce (either exclusively or as a contributing hazard) severe damage in 51 bridges ( 0.9 percent) and 4 bridges ( 0.1 percent) due to severe scour and bridge overtopping, respectively.

\footnotetext{
7 Nearly half (595 bridges) of the bridges projected to experience no damage are exposed to seismic demand during the CSZ scenario exceeding the bridges' operational seismic design capacity, but bridges are expected to suffer no damage due to expected higher capacity because of the existence of pier walls and/or single span.
} 
TABLE 3.-Projected Bridge Damage Types and Levels from CSZ Scenario Earthquake.

\begin{tabular}{|c|c|c|c|c|}
\hline \multirow{2}{*}{$\begin{array}{l}\text { Damage } \\
\text { Level }\end{array}$} & \multicolumn{3}{|c|}{ Damage Level by Damage Type } & \multirow{2}{*}{$\begin{array}{l}\text { Number } \\
\text { of } \\
\text { Bridges }\end{array}$} \\
\hline & Shaking & Liquefaction & Tsunami & \\
\hline \multirow[t]{4}{*}{ None } & \multicolumn{3}{|c|}{ None } & 740 \\
\hline & $\begin{array}{l}\text { None: Seismic demand exceeds bridge's } \\
\text { operational seismic design capacity, but bridge } \\
\text { is expected to suffer no damage due to } \\
\text { expected higher capacity due to existence of } \\
\text { pier walls. }\end{array}$ & \multicolumn{2}{|c|}{ None } & 59 \\
\hline & $\begin{array}{l}\text { None: Seismic demand exceeds bridge's } \\
\text { operational seismic design capacity, but bridge } \\
\text { is expected to suffer no damage due to } \\
\text { expected higher capacity because bridge is a } \\
\text { single span bridge. }\end{array}$ & \multicolumn{2}{|c|}{ None } & 521 \\
\hline & $\begin{array}{l}\text { None: Seismic demand exceeds bridge's } \\
\text { operational seismic design capacity, but bridge } \\
\text { is expected to suffer no damage due to } \\
\text { expected higher capacity because bridge is a } \\
\text { single span bridge and has pier walls. }\end{array}$ & \multicolumn{2}{|c|}{ None } & 15 \\
\hline \multirow[t]{7}{*}{ Moderate } & $\begin{array}{l}\text { Moderate: Seismic demand exceeds bridge's } \\
\text { operational seismic design capacity. }\end{array}$ & \multicolumn{2}{|c|}{ None } & 706 \\
\hline & $\begin{array}{l}\text { Moderate: Seismic demand exceeds bridge's } \\
\text { operational seismic design capacity. }\end{array}$ & $\begin{array}{l}\text { Moderate: Minor } \\
\text { soil liquefaction } \\
\text { occurs at bridge } \\
\text { location. }\end{array}$ & None & 5 \\
\hline & $\begin{array}{l}\text { Moderate: Seismic demand exceeds bridge's } \\
\text { life-safety seismic design capacity, but bridge is } \\
\text { expected to suffer moderate damage due to } \\
\text { expected higher capacity due to existence of } \\
\text { pier walls. }\end{array}$ & \multicolumn{2}{|c|}{ None } & 110 \\
\hline & $\begin{array}{l}\text { Moderate: Seismic demand exceeds bridge's } \\
\text { life-safety seismic design capacity, but bridge is } \\
\text { expected to suffer moderate damage due to } \\
\text { expected higher capacity due to existence of } \\
\text { pier walls. }\end{array}$ & $\begin{array}{l}\text { Moderate: Minor } \\
\text { soil liquefaction } \\
\text { occurs at bridge } \\
\text { location. }\end{array}$ & None & 13 \\
\hline & $\begin{array}{l}\text { Moderate: Seismic demand exceeds bridge's } \\
\text { life-safety seismic design capacity, but bridge is } \\
\text { expected to suffer moderate damage due to } \\
\text { expected higher capacity because bridge is a } \\
\text { single span bridge. }\end{array}$ & \multicolumn{2}{|c|}{ None } & 994 \\
\hline & $\begin{array}{l}\text { Moderate: Seismic demand exceeds bridge's } \\
\text { life-safety seismic design capacity, but bridge is } \\
\text { expected to suffer moderate damage due to } \\
\text { expected higher capacity because bridge is a } \\
\text { single span bridge. }\end{array}$ & $\begin{array}{l}\text { Moderate: Minor } \\
\text { soil liquefaction } \\
\text { occurs at bridge } \\
\text { location. }\end{array}$ & None & 149 \\
\hline & $\begin{array}{l}\text { Moderate: Seismic demand exceeds bridge's } \\
\text { life-safety seismic design capacity, but bridge is } \\
\text { expected to suffer moderate damage due to } \\
\text { expected higher capacity because bridge is a } \\
\text { single span bridge and has pier walls. }\end{array}$ & \multicolumn{2}{|c|}{ None } & 12 \\
\hline
\end{tabular}




\begin{tabular}{|c|c|c|c|c|}
\hline & $\begin{array}{l}\text { Moderate: Seismic demand exceeds bridge's } \\
\text { life-safety seismic design capacity, but bridge is } \\
\text { expected to suffer moderate damage due to } \\
\text { expected higher capacity because bridge is a } \\
\text { single span bridge and has pier walls. }\end{array}$ & $\begin{array}{l}\text { Moderate: Minor } \\
\text { soil liquefaction } \\
\text { occurs at bridge } \\
\text { location. }\end{array}$ & None & 2 \\
\hline & None & $\begin{array}{l}\text { Moderate: Minor } \\
\text { soil liquefaction } \\
\text { occurs at bridge } \\
\text { location. }\end{array}$ & None & 4 \\
\hline & $\begin{array}{l}\text { None: Seismic demand exceeds bridge's } \\
\text { operational seismic design capacity, but bridge } \\
\text { is expected to suffer no damage from shaking } \\
\text { due to expected higher capacity due to } \\
\text { existence of pier walls. }\end{array}$ & $\begin{array}{l}\text { Moderate: Minor } \\
\text { soil liquefaction } \\
\text { occurs at bridge } \\
\text { location. }\end{array}$ & None & 2 \\
\hline & $\begin{array}{l}\text { None: Seismic demand exceeds bridge's } \\
\text { operational seismic design capacity, but bridge } \\
\text { is expected to suffer no damage from shaking } \\
\text { due to expected higher capacity because } \\
\text { bridge is a single span bridge. }\end{array}$ & $\begin{array}{l}\text { Moderate: Minor } \\
\text { soil liquefaction } \\
\text { occurs at bridge } \\
\text { location. }\end{array}$ & None & 15 \\
\hline \multirow[t]{9}{*}{ Severe } & $\begin{array}{l}\text { Severe: Seismic demand exceeds bridge's } \\
\text { reduced seismic capacity (reduced due to } \\
\text { bridge having precast concrete piles). }\end{array}$ & \multicolumn{2}{|c|}{ None } & 127 \\
\hline & $\begin{array}{l}\text { Severe: Seismic demand exceeds bridge's } \\
\text { reduced seismic capacity (reduced due to } \\
\text { bridge having precast concrete piles). }\end{array}$ & $\begin{array}{l}\text { Severe: Major soil } \\
\text { liquefaction occurs } \\
\text { at bridge location. }\end{array}$ & None & 21 \\
\hline & $\begin{array}{l}\text { Severe: Seismic demand exceeds bridge's } \\
\text { reduced seismic capacity (reduced due to } \\
\text { bridge having precast concrete piles). }\end{array}$ & $\begin{array}{l}\text { Severe: Major soil } \\
\text { liquefaction occurs } \\
\text { at bridge location. }\end{array}$ & $\begin{array}{l}\text { Severe: Tsunami } \\
\text { waves at bridge } \\
\text { location cause } \\
\text { severe scour } \\
\text { damage. }\end{array}$ & 1 \\
\hline & $\begin{array}{l}\text { Severe: Seismic demand exceeds bridge's } \\
\text { reduced seismic capacity (reduced due to } \\
\text { bridge having precast concrete piles). }\end{array}$ & $\begin{array}{l}\text { Moderate: Minor } \\
\text { soil liquefaction } \\
\text { occurs at bridge } \\
\text { location. }\end{array}$ & None & 10 \\
\hline & $\begin{array}{l}\text { Severe: Seismic demand exceeds bridge's } \\
\text { reduced seismic capacity (reduced due to } \\
\text { bridge having precast concrete piles). }\end{array}$ & $\begin{array}{l}\text { Moderate: Minor } \\
\text { soil liquefaction } \\
\text { occurs at bridge } \\
\text { location. }\end{array}$ & $\begin{array}{l}\text { Severe: Tsunami } \\
\text { waves at bridge } \\
\text { location cause } \\
\text { severe scour } \\
\text { damage. }\end{array}$ & 1 \\
\hline & $\begin{array}{l}\text { Severe: Seismic demand exceeds bridge's life- } \\
\text { safety seismic design capacity. }\end{array}$ & \multicolumn{2}{|c|}{ None } & 990 \\
\hline & $\begin{array}{l}\text { Severe: Seismic demand exceeds bridge's life- } \\
\text { safety seismic design capacity. }\end{array}$ & $\begin{array}{l}\text { Severe: Major soil } \\
\text { liquefaction occurs } \\
\text { at bridge location. }\end{array}$ & None & 353 \\
\hline & $\begin{array}{l}\text { Severe: Seismic demand exceeds bridge's life- } \\
\text { safety seismic design capacity. }\end{array}$ & $\begin{array}{l}\text { Severe: Major soil } \\
\text { liquefaction occurs } \\
\text { at bridge location. }\end{array}$ & $\begin{array}{l}\text { Severe: Bridge is } \\
\text { overtopped by } \\
\text { tsunami waves. }\end{array}$ & 2 \\
\hline & $\begin{array}{l}\text { Severe: Seismic demand exceeds bridge's life- } \\
\text { safety seismic design capacity. }\end{array}$ & $\begin{array}{l}\text { Severe: Major soil } \\
\text { liquefaction occurs } \\
\text { at bridge location. }\end{array}$ & $\begin{array}{l}\text { Severe: Tsunami } \\
\text { waves at bridge } \\
\text { location cause } \\
\text { severe scour } \\
\text { damage. }\end{array}$ & 23 \\
\hline
\end{tabular}




\begin{tabular}{|c|c|c|c|}
\hline $\begin{array}{l}\text { Severe: Seismic demand exceeds bridge's life- } \\
\text { safety seismic design capacity. }\end{array}$ & None & $\begin{array}{l}\text { Severe: Tsunami } \\
\text { waves at bridge } \\
\text { location cause } \\
\text { severe scour } \\
\text { damage. }\end{array}$ & 4 \\
\hline $\begin{array}{l}\text { Severe: Seismic demand exceeds bridge's life- } \\
\text { safety seismic design capacity. }\end{array}$ & $\begin{array}{l}\text { Moderate: Minor } \\
\text { soil liquefaction } \\
\text { occurs at bridge } \\
\text { location. }\end{array}$ & None & 158 \\
\hline $\begin{array}{l}\text { Severe: Seismic demand exceeds bridge's life- } \\
\text { safety seismic design capacity. }\end{array}$ & $\begin{array}{l}\text { Moderate: Minor } \\
\text { soil liquefaction } \\
\text { occurs at bridge } \\
\text { location. }\end{array}$ & $\begin{array}{l}\text { Severe: Tsunami } \\
\text { waves at bridge } \\
\text { location cause } \\
\text { severe scour } \\
\text { damage. }\end{array}$ & 2 \\
\hline None & $\begin{array}{l}\text { Severe: Major soil } \\
\text { liquefaction occurs } \\
\text { at bridge location. }\end{array}$ & None & 12 \\
\hline $\begin{array}{l}\text { Moderate: Seismic demand exceeds bridge's } \\
\text { life-safety seismic design capacity, but bridge is } \\
\text { expected to suffer moderate damage due to } \\
\text { expected higher capacity because bridge is a } \\
\text { single span bridge. }\end{array}$ & $\begin{array}{l}\text { Severe: Major soil } \\
\text { liquefaction occurs } \\
\text { at bridge location. }\end{array}$ & $\begin{array}{l}\text { Severe: Bridge is } \\
\text { overtopped by } \\
\text { tsunami waves. }\end{array}$ & 2 \\
\hline $\begin{array}{l}\text { Moderate: Seismic demand exceeds bridge's } \\
\text { life-safety seismic design capacity, but bridge is } \\
\text { expected to suffer moderate damage due to } \\
\text { expected higher capacity due to existence of } \\
\text { pier walls. }\end{array}$ & $\begin{array}{l}\text { Severe: Major soil } \\
\text { liquefaction occurs } \\
\text { at bridge location. }\end{array}$ & $\begin{array}{l}\text { Severe: Tsunami } \\
\text { waves at bridge } \\
\text { location cause } \\
\text { severe scour } \\
\text { damage. }\end{array}$ & 3 \\
\hline $\begin{array}{l}\text { Moderate: Seismic demand exceeds bridge's } \\
\text { life-safety seismic design capacity, but bridge is } \\
\text { expected to suffer moderate damage due to } \\
\text { expected higher capacity because bridge is a } \\
\text { single span bridge. }\end{array}$ & $\begin{array}{l}\text { Severe: Major soil } \\
\text { liquefaction occurs } \\
\text { at bridge location. }\end{array}$ & $\begin{array}{l}\text { Severe: Tsunami } \\
\text { waves at bridge } \\
\text { location cause } \\
\text { severe scour } \\
\text { damage. }\end{array}$ & 14 \\
\hline $\begin{array}{l}\text { Moderate: Seismic demand exceeds bridge's } \\
\text { life-safety seismic design capacity, but bridge is } \\
\text { expected to suffer moderate damage due to } \\
\text { expected higher capacity due to existence of } \\
\text { pier walls. }\end{array}$ & $\begin{array}{l}\text { Severe: Major soil } \\
\text { liquefaction occurs } \\
\text { at bridge location. }\end{array}$ & None & 47 \\
\hline $\begin{array}{l}\text { Moderate: Seismic demand exceeds bridge's } \\
\text { life-safety seismic design capacity, but bridge is } \\
\text { expected to suffer moderate damage due to } \\
\text { expected higher capacity because bridge is a } \\
\text { single span bridge. }\end{array}$ & $\begin{array}{l}\text { Severe: Major soil } \\
\text { liquefaction occurs } \\
\text { at bridge location. }\end{array}$ & None & 483 \\
\hline $\begin{array}{l}\text { Moderate: Seismic demand exceeds bridge's } \\
\text { life-safety seismic design capacity, but bridge is } \\
\text { expected to suffer moderate damage due to } \\
\text { expected higher capacity because bridge is a } \\
\text { single span bridge and has pier walls. }\end{array}$ & $\begin{array}{l}\text { Severe: Major soil } \\
\text { liquefaction occurs } \\
\text { at bridge location. }\end{array}$ & None & 13 \\
\hline $\begin{array}{l}\text { None: Seismic demand exceeds bridge's } \\
\text { operational seismic design capacity, but bridge } \\
\text { is expected to suffer no damage from shaking } \\
\text { due to expected higher capacity because } \\
\text { bridge is a single span bridge. }\end{array}$ & $\begin{array}{l}\text { Severe: Major soil } \\
\text { liquefaction occurs } \\
\text { at bridge location. }\end{array}$ & None & 7 \\
\hline
\end{tabular}




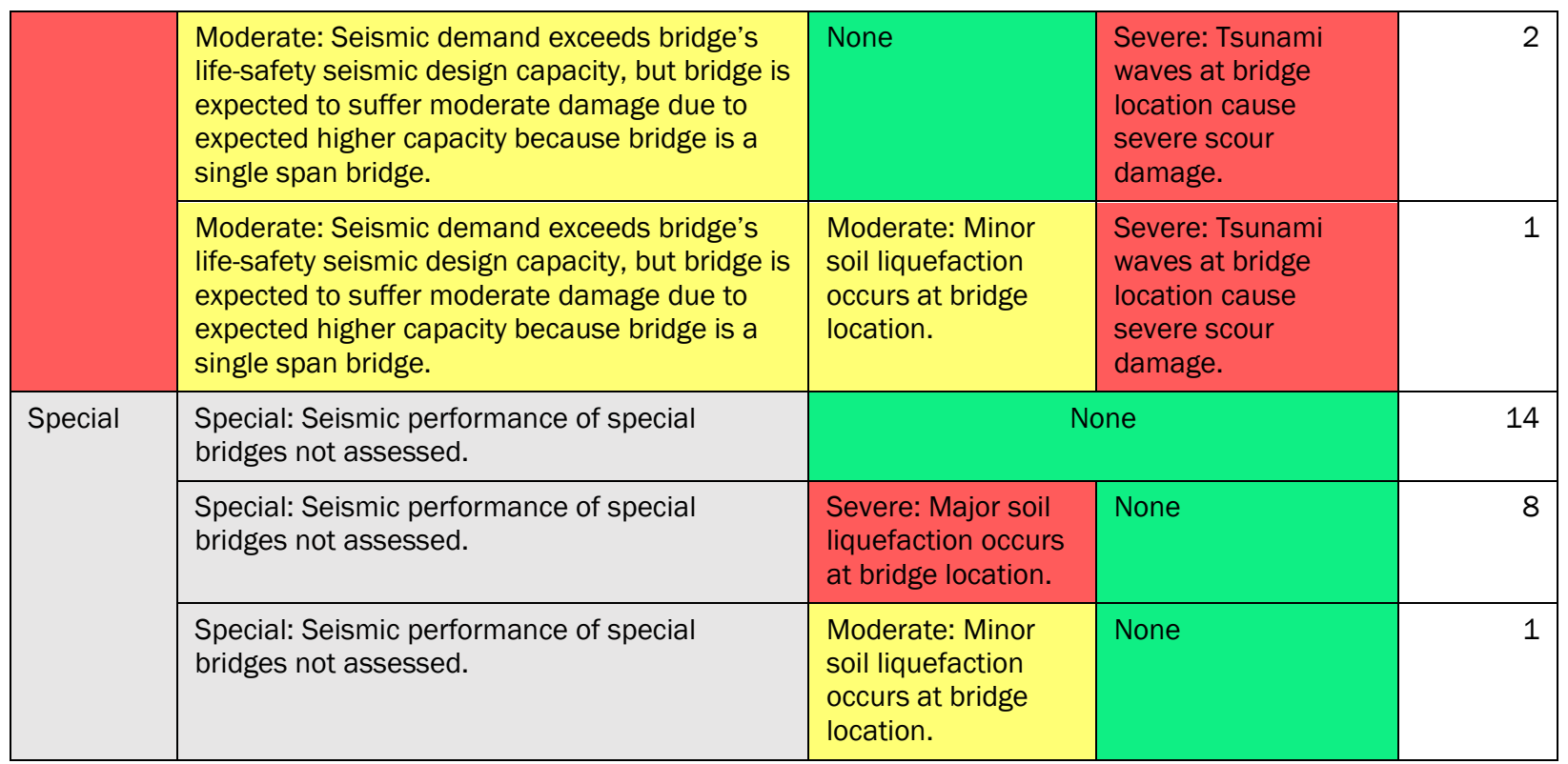


Figures 4 and 5 shows the geographical distribution of state-owned and non-state-owned bridges throughout Oregon with their projected damage types. Nearly all state-owned bridges along Interstate 5 (I-5) and west of this corridor are projected to experience severe damage. Likewise, most of the non-state-owned bridges projected to experience severe damage are located west of the 1-5 corridor. Nearly all of the state-owned and non-state-owned bridges located in or east of the Cascade Mountains are projected to experience minimal damage. Finally, most of the state-owned bridges projected to experience moderate damage are located between the $1-5$ corridor and the Cascade Mountains, while non-state-owned bridges projected to experience moderate damage are more widely distributed across the region of Oregon west of the Cascade Mountains.

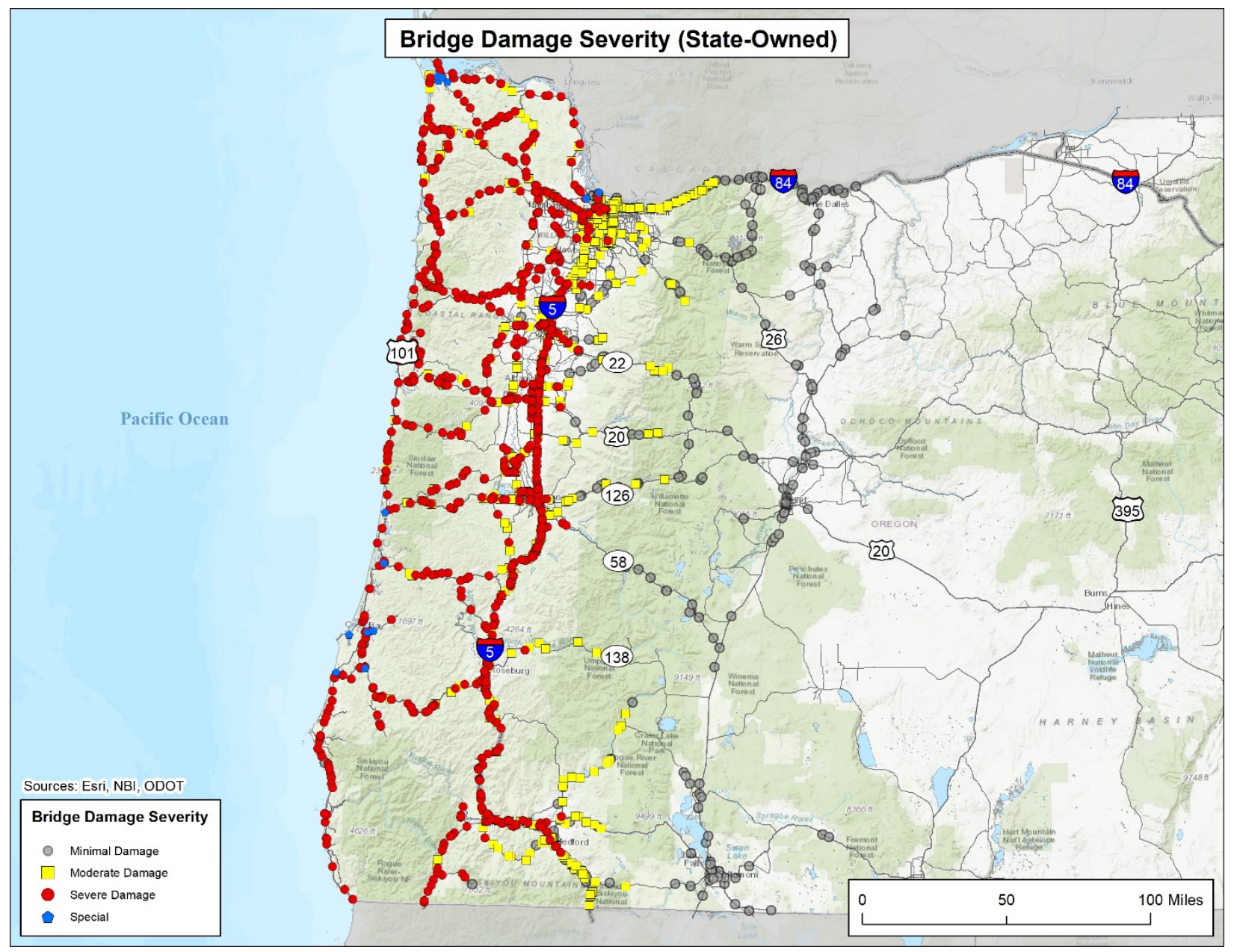

FIGURE 4.-Bridge Seismic Screening Tool (BSST) Projected Damage Severity for State-owned Bridges in Oregon from the CSZ Scenario Earthquake. 


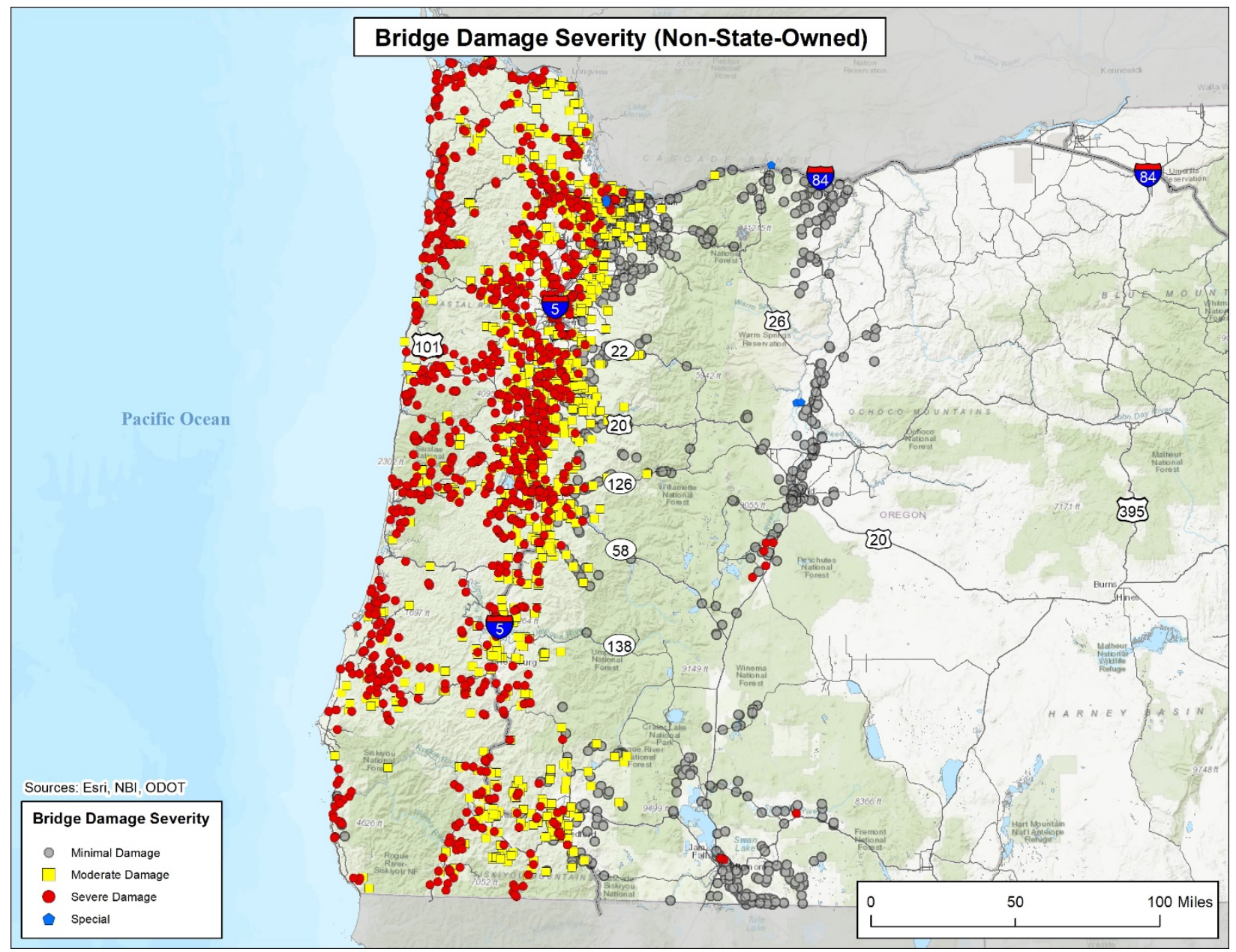

FIGURE 5.-BSST Projected Damage Severity for Non-state-owned Bridges in Oregon from the CSZ Scenario Earthquake.

The following sections provide greater detail on bridges projected to experience damage during the CSZ scenario earthquake.

\section{Severe Damage}

Of the 5,646 bridges evaluated in Oregon, 1,285 bridges (22.8 percent) are projected to experience severe damage exclusively due to inadequate seismic design. Of these bridges, 1,148 (20.3 percent of bridges assessed) are projected to experience PGA exceeding their life-safety design level and 137 (2.4 percent of bridges assessed) are expected to experience severe damage due to seismic demand exceeding the bridge's limited seismic capacity associated with the existence of precast concrete piles. An additional 562 bridges (10.0 percent of bridges assessed) are projected to experience severe damage exclusively due to major liquefaction occurring at the bridge location, while 3 bridges are expected to experience severe damage exclusively due to severe scour due to tsunami waves at the bridge location. Finally, 426 bridges ( 7.5 percent of the bridges assessed) are projected to experience severe damage due to some combination of inadequate seismic design, existence of precast concrete piles, major liquefaction in soil at bridge location, and scour damage or overtopping due to tsunami waves at bridge location. The rest of this section provides greater context on the extent of specific damage types projected for bridges in Oregon. 
Inadequate seismic design is the single most prevalent driver of severe damage in assessed bridges in Oregon, causing severe damage in 1,692 bridges (30 percent of assessed bridges), of which 955 are state-owned (38.6 percent of assessed state-owned bridges) and 737 are non-state-owned (23.2 percent of assessed non-state-owned bridges). Breaking this down further, 1,532 bridges (27.1 percent of assessed bridges) are projected to experience severe damage due to PGA during the CSZ scenario exceeding the bridge's life-safety seismic design capacity, of which 880 are stateowned (35.6 percent of assessed state-owned bridges) and 652 are non-state-owned (20.5 percent of assessed non-state-owned bridges). Furthermore, 160 bridges (2.8 percent of assessed bridges) are projected to experience severe damage due to seismic demand exceeding the bridge's limited seismic capacity associated with the existence of precast concrete piles, of which 75 are stateowned (3.0 percent of assessed state-owned bridges) and 85 are non-state-owned (2.7 percent of assessed non-state-owned bridges). Figures 6 and 7 show the distribution of state and non-stateowned bridges, respectively, projected to experience severe damage as a direct result of inadequate seismic design. As these maps show, nearly all of these bridges are located along or to the west of the $1-5$ corridor.

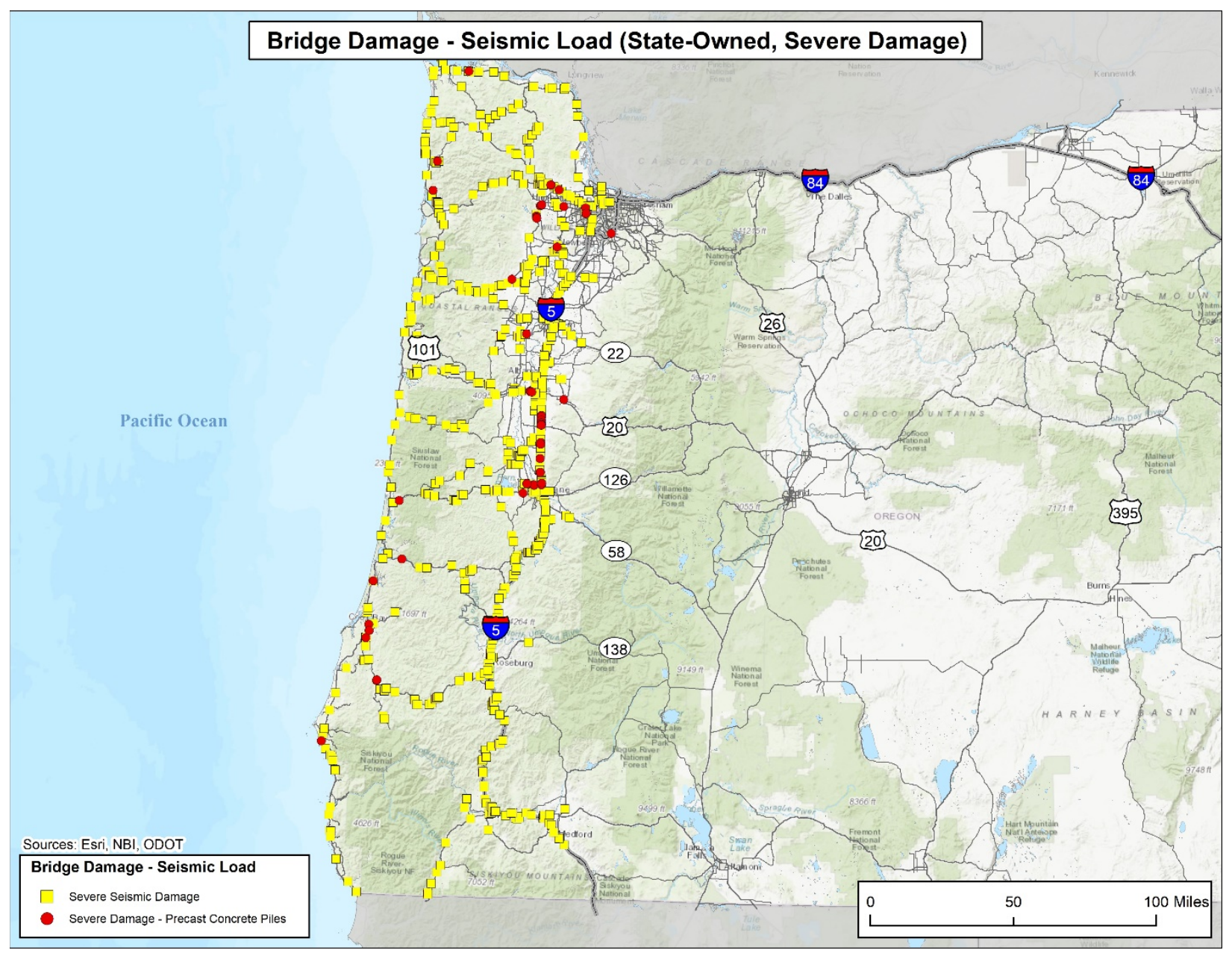

FIGURE 6.-State-owned Bridges in Oregon Projected by BSST to Experience Severe Damage from the CSZ Scenario Earthquake Due to Inadequate Seismic Design. 


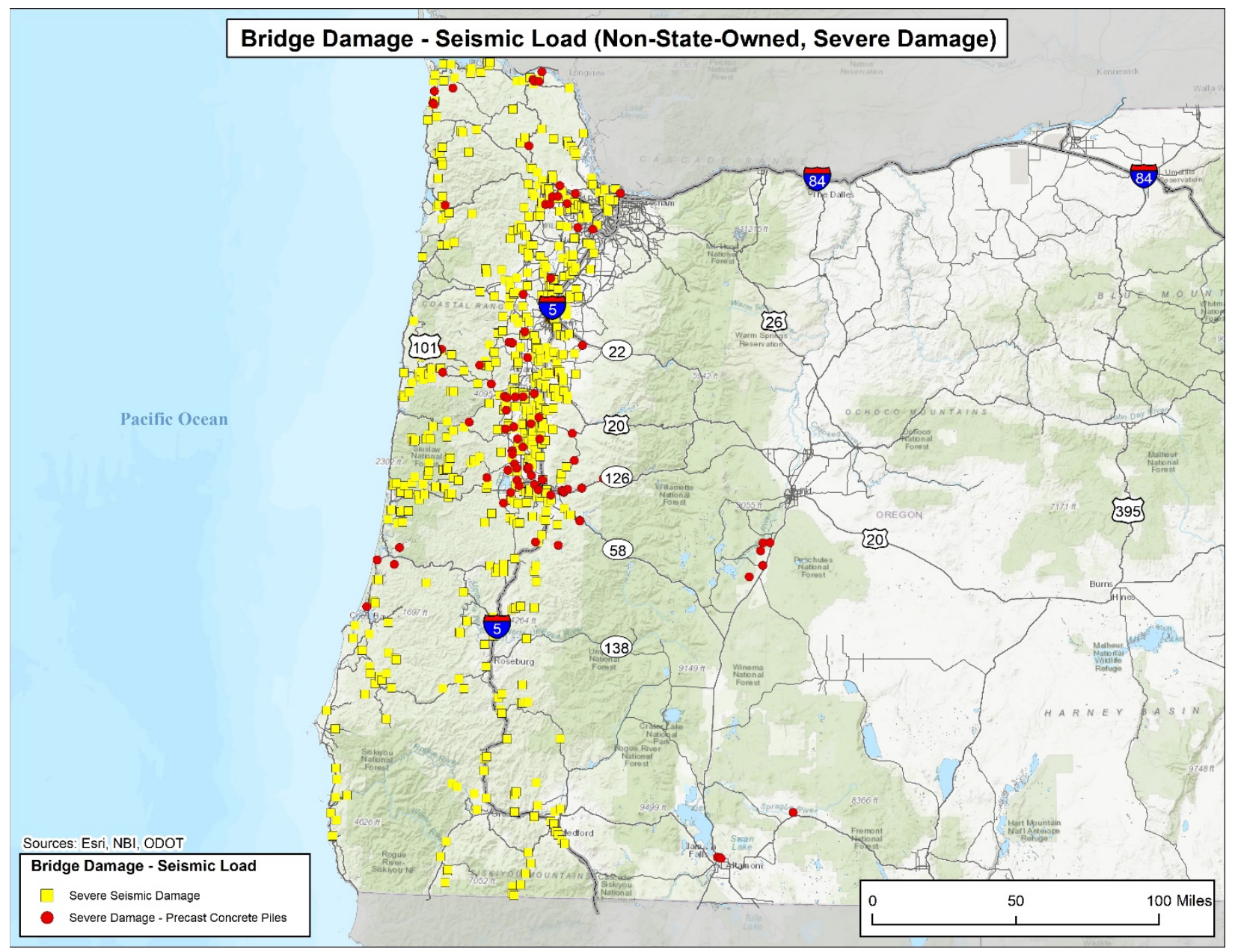

FIGURE 7.-Non-state-owned Bridges in Oregon Projected by BSST to Experience Severe Damage from the CSZ Scenario Earthquake Due to Inadequate Seismic Design.

Liquefaction is the second most prevalent cause of severe damage in Oregon bridges, causing severe damage in 989 bridges (17.5 percent) in Oregon. Breaking this down further, 409 stateowned bridges (16.6 percent of all state-owned bridges assessed in Oregon) and 580 non-stateowned bridges (18.3 percent of all non-state-owned bridges assessed in Oregon) are projected to experience severe damage due to major liquefaction at the bridge location. Figures 8 and 9 show the projected liquefaction damage of state and non-state-owned bridges in Oregon, respectively. These figures reveal that nearly all bridges projected to experience major liquefaction are located on or west of the $1-5$ corridor. Further discussion of minor liquefaction damage is provided in the Moderate Damage section. 


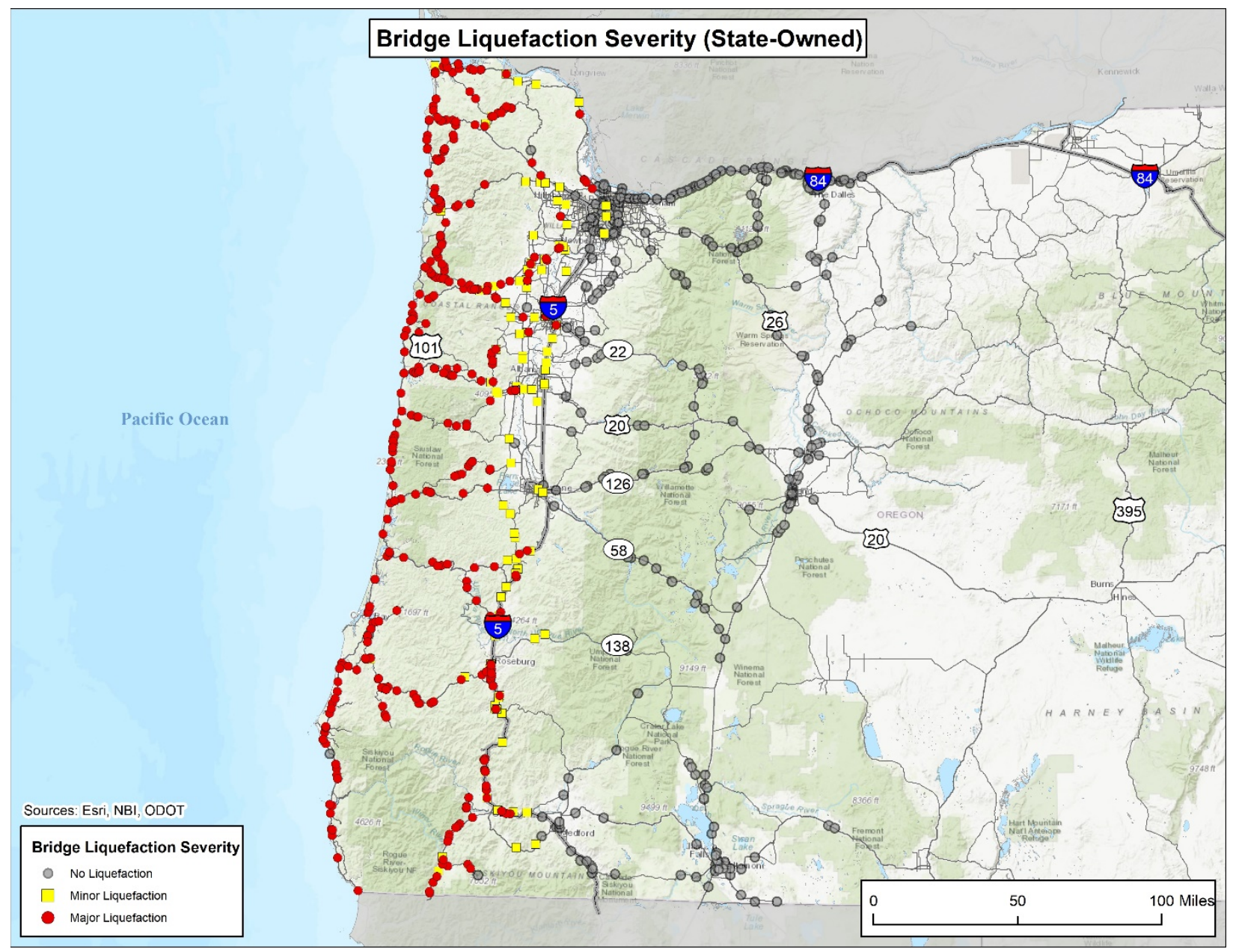

FIGURE 8.-BSST Projected Liquefaction Damage for State-owned Bridges in Oregon from the CSZ Scenario Earthquake. 


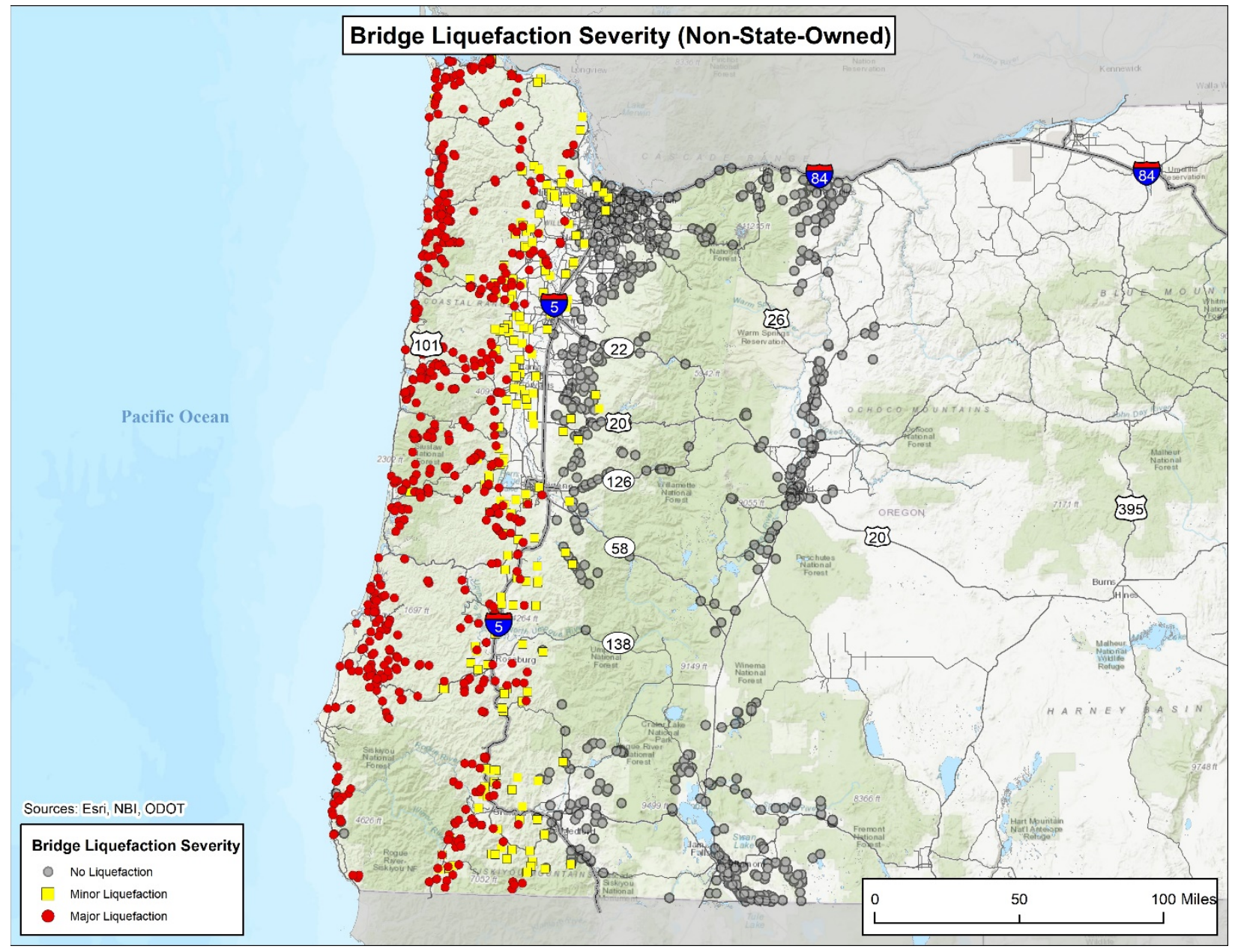

FIGURE 9.-BSST Projected Liquefaction Damage for Non-state-owned Bridges in Oregon from the CSZ Scenario Earthquake.

Finally, while more than 300 bridges fall within projected tsunami inundation areas, only 55 bridges (1.0 percent of assessed bridges) in Oregon are projected to experience severe damages due to a tsunami. Of those bridges, 4 state-owned bridges are projected to experience severe damage due to overtopping during tsunami, and 21 state-owned ( 0.8 percent of the state-owned bridges assessed) and 30 non-state-owned ( 0.9 percent of the non-state-owned bridges assessed) bridges are projected to experience severe damage due to severe scour caused by tsunami waves at the bridge location. Figure 10 shows the location of state and non-state-owned bridges projected to experience tsunami-induced severe damage, nearly all of which are located along the Pacific coast. 


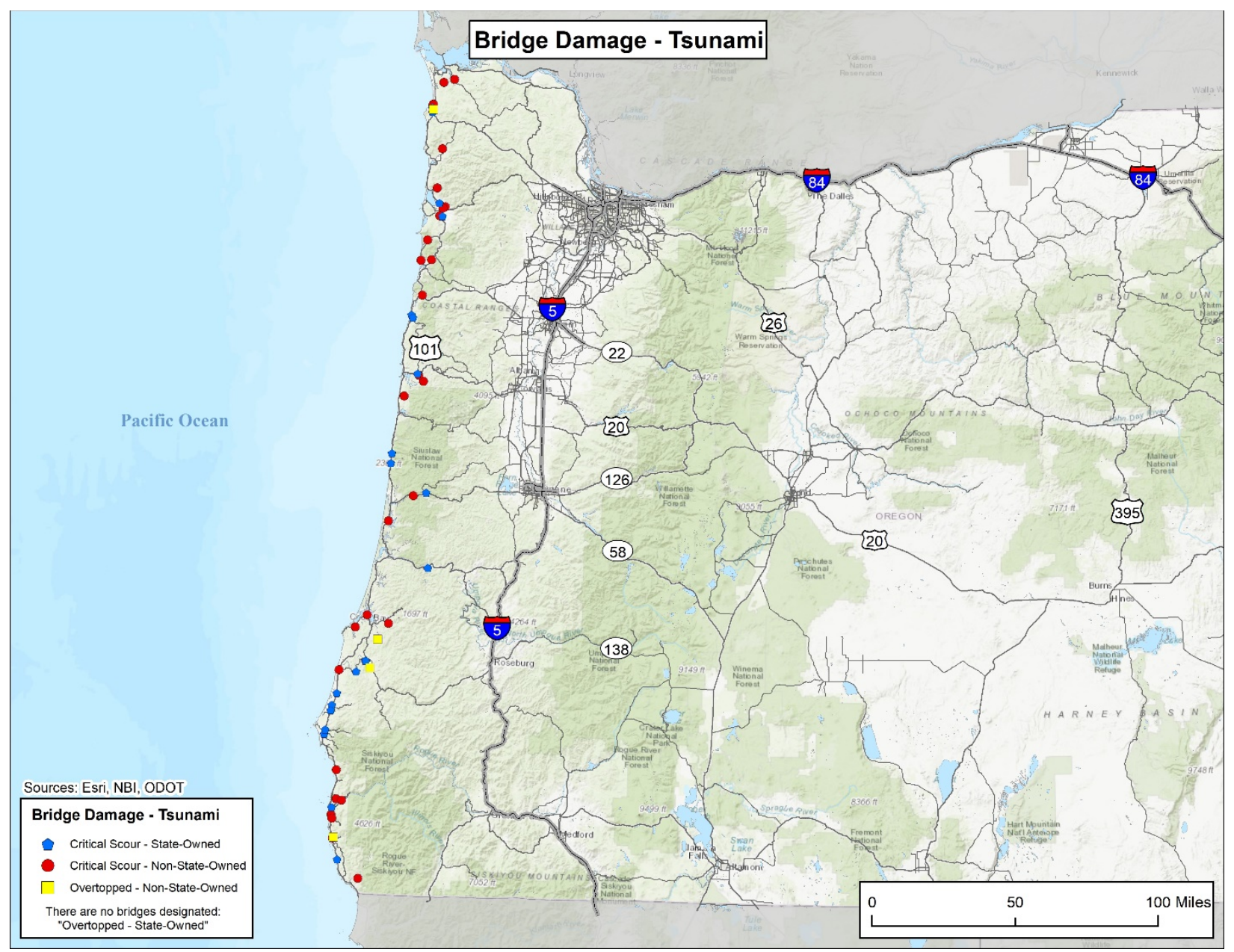

FIGURE 10.-BSST Projected Tsunami Damage for Bridges in Oregon from the CSZ Scenario Earthquake.

\section{Moderate Damage}

Of the 5,646 bridges evaluated, 1,822 bridges (32.3 percent) are projected to experience moderate damage exclusively as a result of inadequate seismic design. Of these bridges, 706 (12.5 percent of the assessed bridges) are exposed to seismic demand during the CSZ scenario exceeding the bridge's operational seismic demand capacity but less than the bridge's life-safety design capacity. Others are bridges where the CSZ scenario PGA at the bridge site exceeds the bridge's life-safety seismic demand capacity, but the bridge is projected to experience moderate damage (rather than severe damage) because the bridge has a single span (994 bridges, 17.6 percent of the assessed bridges), pier walls (110 bridges, 1.9 percent of assessed bridges), or both single span and pier walls (12 bridges, 0.2 percent of assessed bridges). Minor liquefaction causes moderate damage in 21 bridges ( 0.4 percent of bridges). Finally, 169 bridges (3.0 percent) are projected to experience moderate damage due to a combination of inadequate seismic design and minor liquefaction in the soil at the bridge location. The rest of this section provides more details on the project seismic demand and liquefaction damage.

Inadequate seismic design is the primary driver of moderate damage in assessed Oregon bridges, causing moderate damage in 1,991 bridges (35.3 percent of assessed bridges), of which 807 are state-owned (32.7 percent of assessed state-owned bridges) and 1,184 are non-state-owned 
(37.3 percent of assessed non-state-owned bridges). The majority of these bridges (1,143 bridges, accounting for 20.2 percent of the assessed bridges) are exposed to a CSZ scenario PGA exceeding the bridge's life-safety seismic demand capacity, but are projected to experience moderate damage (rather than severe damage) due to a single span design; of these bridges, 284 are state-owned (11.5 percent of assessed state-owned bridges) and 859 are non-state-owned (27.1 percent of assessed non-state-owned bridges). Furthermore, 711 bridges (12.6 percent of the assessed bridges) experience moderate damage due to exposure to seismic demand during the CSZ scenario exceeding the bridge's operational seismic demand capacity but less than the bridge's life-safety design capacity, of which 461 are state-owned (18.7 percent of assessed state-owned bridges) and 250 are non-state-owned ( 7.9 percent of assessed non-state-owned bridges). An additional 123 bridges (2.2 percent of the assessed bridges) are exposed to a CSZ scenario PGA exceeding the bridge's life-safety seismic demand capacity, but are projected to experience moderate damage (rather than severe damage) due to the existence of pier walls; of these bridges, 58 are state-owned (2.3 percent of assessed state-owned bridges) and 65 are non-state-owned ( 2.0 percent of assessed non-state-owned bridges). Similarly, 14 bridges ( 0.2 percent of the assessed bridges) are exposed to a CSZ scenario PGA exceeding the bridge's life-safety seismic demand capacity, but are projected to experience moderate damage (rather than severe damage) due to the existence of pier walls and a single span design; of these bridges, 4 are state-owned (0.2 percent of assessed state-owned bridges) and 10 are non-state-owned ( 0.3 percent of assessed non-state-owned bridges). Finally, an additional 565 bridges (165 of which are state-owned and 400 are non-state-owned) are projected to experience moderate seismic-induced damage (i.e., seismic demand exceeding seismic capacity), but these bridges are projected to experience severe damage due to major liquefaction at bridge location or due to overtopping or severe scour caused by tsunami waves at the bridge location. Figures 11 and 12 shows the distribution of state and non-state-owned bridges, respectively, projected to experience moderate seismic-induced damage. As expected, nearly all of the bridges exposed to PGA during the CSZ scenario exceeding their life-safety seismic design are generally located along or west of the I-5 corridor, whereas bridges exposed to PGA exceeding their operational seismic design are located generally east of the $1-5$ corridor. 


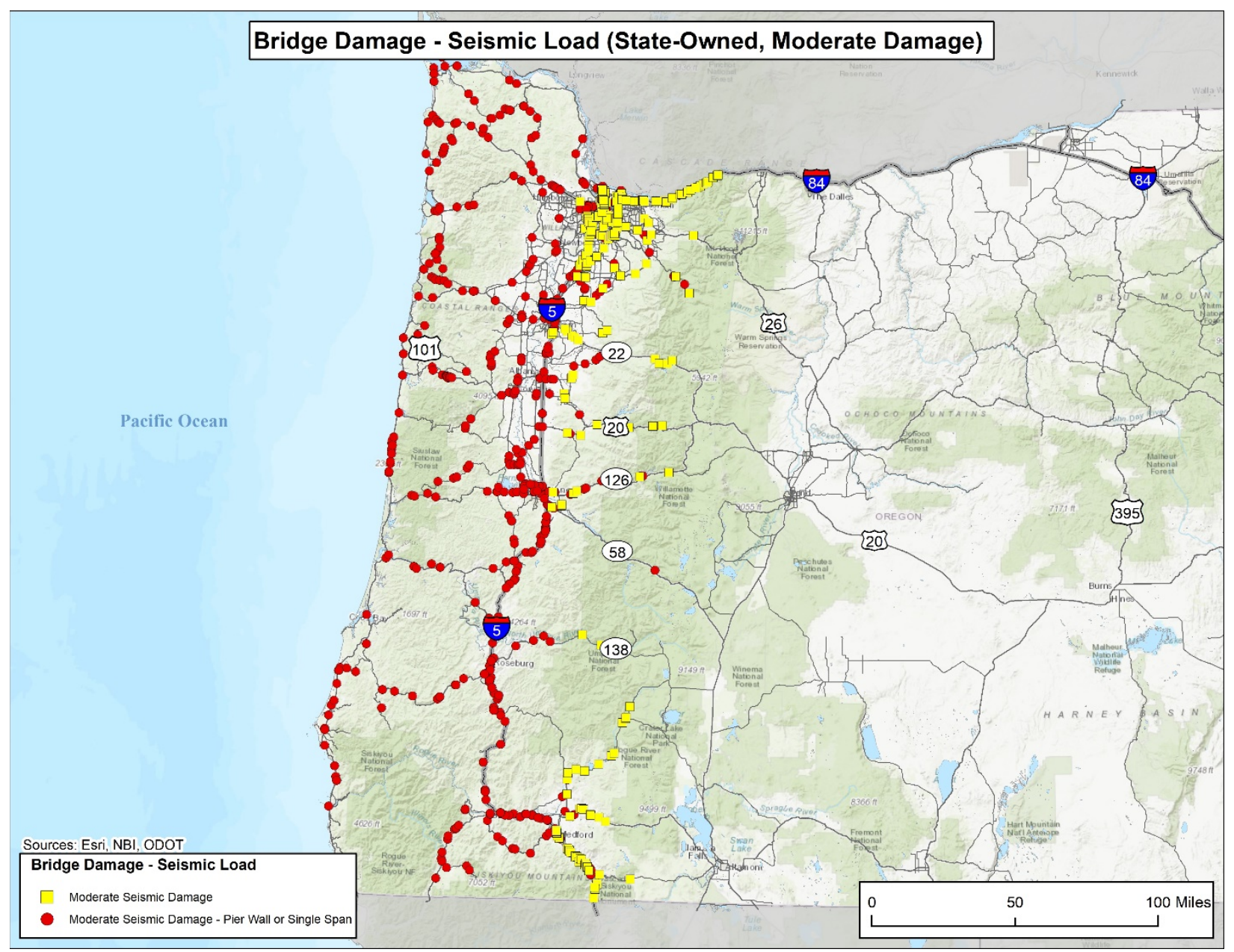

FIGURE 11.-BSST Projected Moderate Shaking Damage for State-owned Bridges in Oregon from the CSZ Scenario Earthquake. 


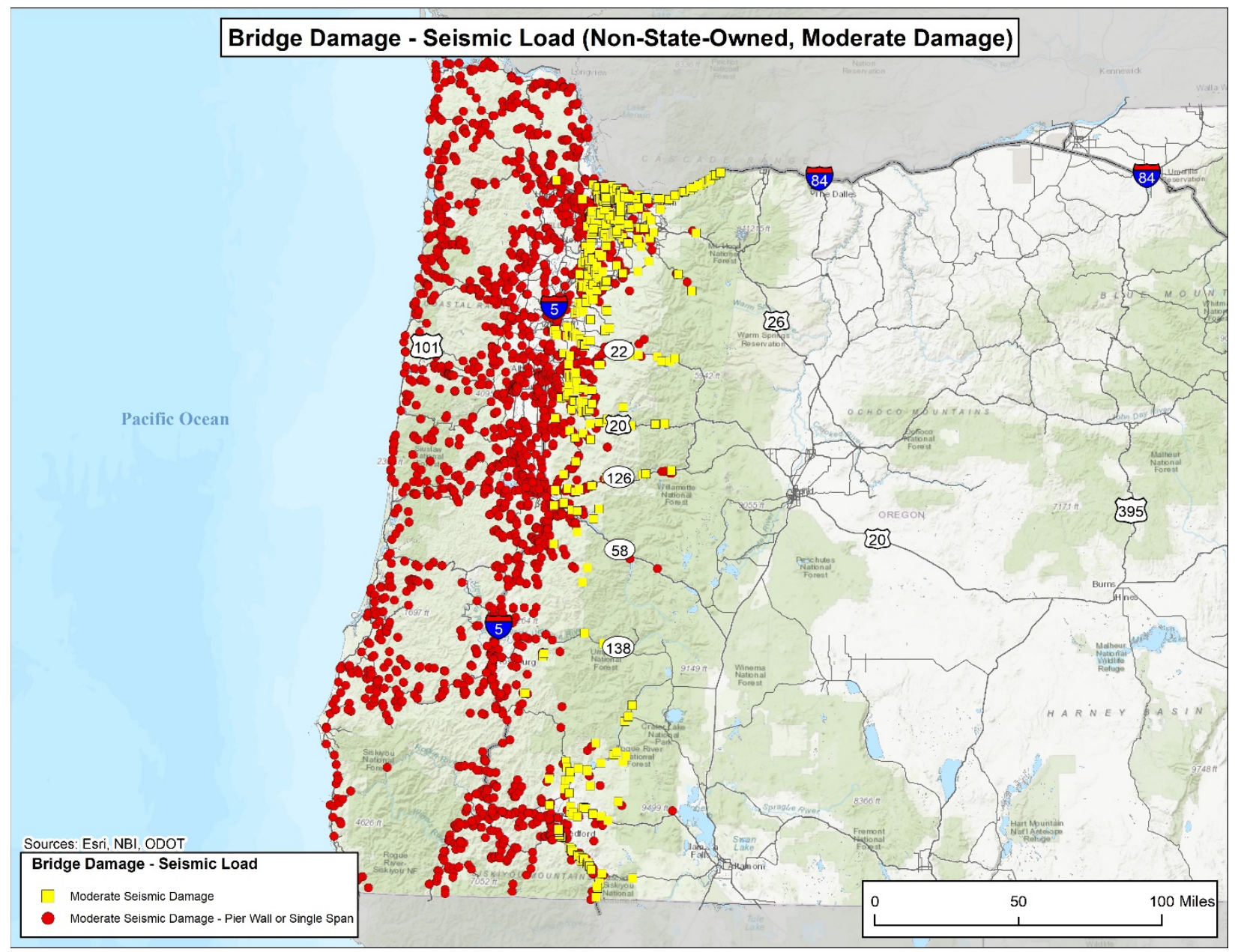

FIGURE 12.-BSST Projected Moderate Shaking Damage for Non-state-owned Bridges in Oregon from the CSZ Scenario Earthquake.

Minor liquefaction induces moderate damage in 190 bridges (3.4 percent of the assessed bridges). Of these bridges, 49 are state-owned (2.0 percent of assessed state-owned bridges) and 141 are non-state-owned (4.4 percent of assessed non-state-owned bridges). An additional 173 bridges (91 of which are state-owned and 82 are non-state-owned) are projected to experience minor liquefaction, but these bridges are projected to experience severe damage due to inadequate seismic design or severe scour caused by tsunami waves at the bridge location. Figures 8 and 9 show the location of bridges projected by the BSST to experience minor liquefaction.

\section{Bridge Damage Repair Types}

The projected repair types and reopening times necessary to bring bridges back to a minimum level of functionality that enables their use for emergency response were computed using the methodology specified in the Bridge Reopening Times section. Table 4 provides a summary of the projected repair types. The 2,012 bridges (35.6 percent of all bridges assessed) projected to experience moderate damage during the CSZ scenario earthquake are projected in the BSST to require inspection and potential minor repair. Of the bridges that require some level of intervention greater than inspection and minor repair, the majority (1,839 bridges, 32.6 percent of the assessed bridges) are crossings over water that could require a new bridge to be built; 909 of these crossings are also proximate to projected major liquefaction that could require subsurface stabilization or 
strengthening prior to the construction of a new bridge. Some bridges projected to experience severe damage (422, or 7.5 percent of the assessed bridges) can be reopened by implementing a temporary roadway that bypasses the damaged bridge. An example of this would be a collapsed highway overpass, where a temporary roadway is constructed with a surface intersection between the mainline and intersecting roadways. Finally, 15 bridges ( 0.3 percent of the assessed bridges) are crossings over steep terrain that could require a new bridge to be built; 1 of these crossings is also proximate to projected major liquefaction that could require subsurface stabilization or strengthening prior to the construction of a new bridge.

TABLE 4.-Projected Bridge Repair Types after CSZ Scenario Earthquake.

\begin{tabular}{|l|r|}
\hline Repair Type & Number of Bridges \\
\hline None & 1,335 \\
\hline Bridge Inspection with Potential Minor Repairs & 2,012 \\
\hline Temporary Road to Bypass Bridge & 422 \\
\hline New Bridge over Water & 930 \\
\hline New Bridge over Impassable Topography & 14 \\
\hline New Bridge over Water with Subsurface Strengthening & 909 \\
\hline New Bridge over Impassable Topography with Subsurface Strengthening & 1 \\
\hline New Special Bridge & 23 \\
\hline
\end{tabular}

Figures 13 through 16 show the geographical distribution of state and non-state-owned bridges in Oregon according to their projected repair types. Figures 13 and 15 show the location of state and non-state-owned bridges, respectively, projected to experience severe damage that necessitates the construction of a new bridge. These figures show that nearly all of the bridge locations requiring a new bridge and subsurface strengthening are located west of the $1-5$ corridor. As discussed in the Special Bridge Design Identification section, the BSST assumes special design bridges are severely damaged and will require replacement following the CSZ scenario earthquake; as such, state and non-state-owned special design bridges are included in figures 13 and 15, respectively. Figures 14 and 16 show the location of state and non-state-owned bridges, respectively, projected to experience moderate damage or projected to experience severe damage but for which the BSST projects the construction of a new bridge will not be required. The BSST projects that the majority of state-owned bridges along the 1-5 corridor experiencing severe damage can be bypassed with a temporary roadway, while very few non-state-owned bridges can be bypassed with a temporary roadway. 


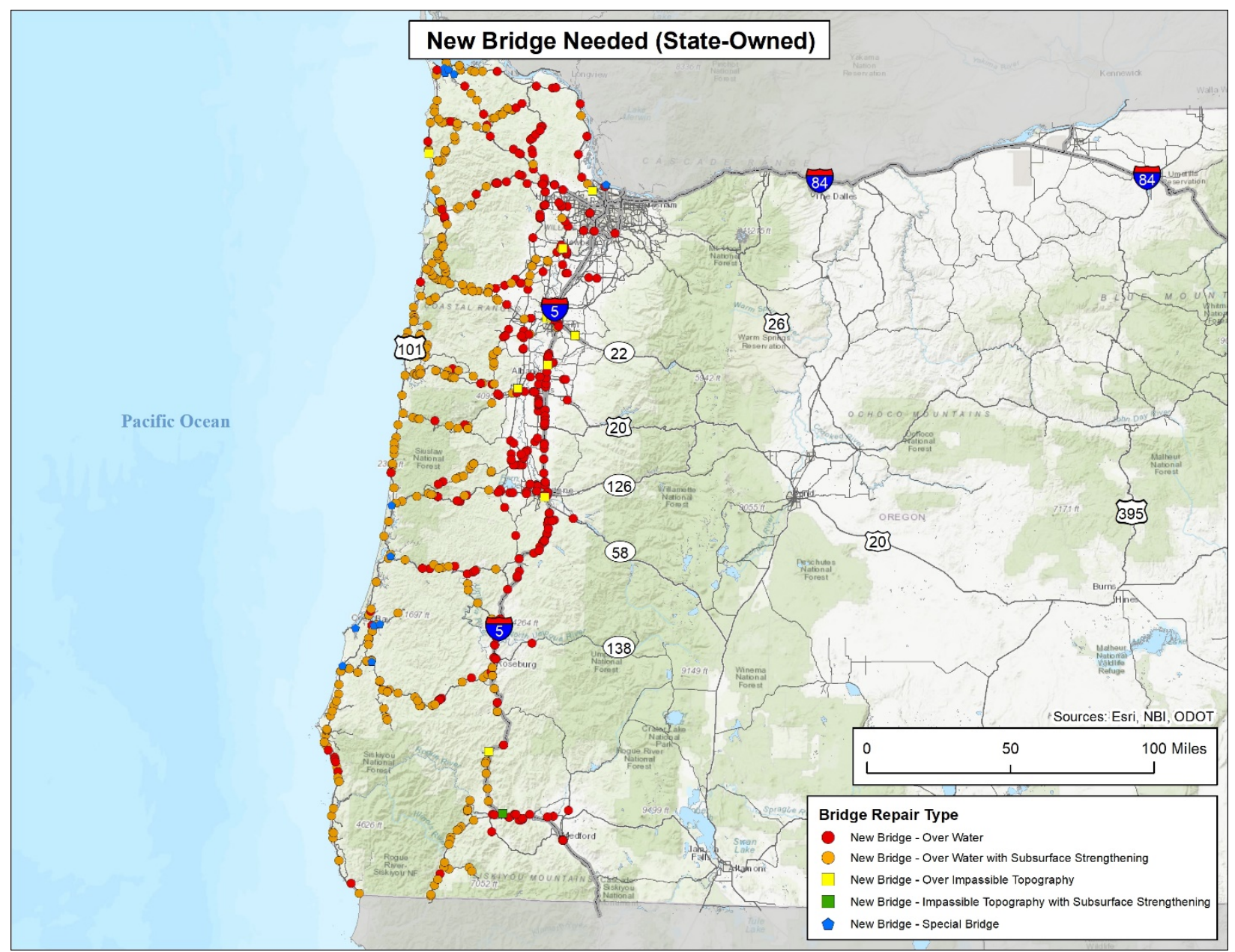

FIGURE 13.-State-owned Bridges in Oregon Projected by the BSST to Experience Severe Damage Requiring Construction of a New Bridge after the CSZ Scenario Earthquake. 


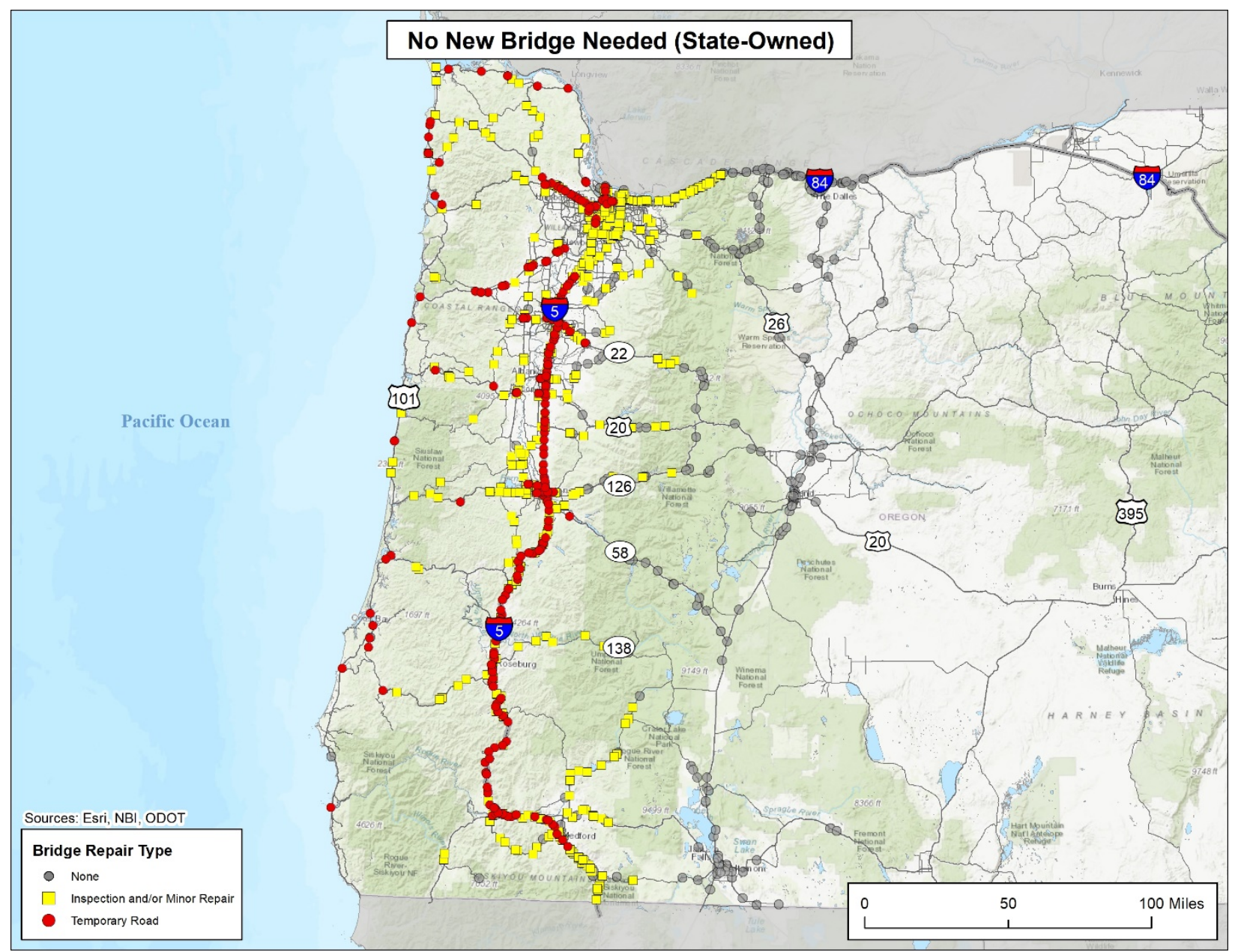

FIGURE 14.-State-owned Bridges in Oregon Projected by the BSST to Not Require the Construction of a New Bridge after the CSZ Scenario Earthquake. 


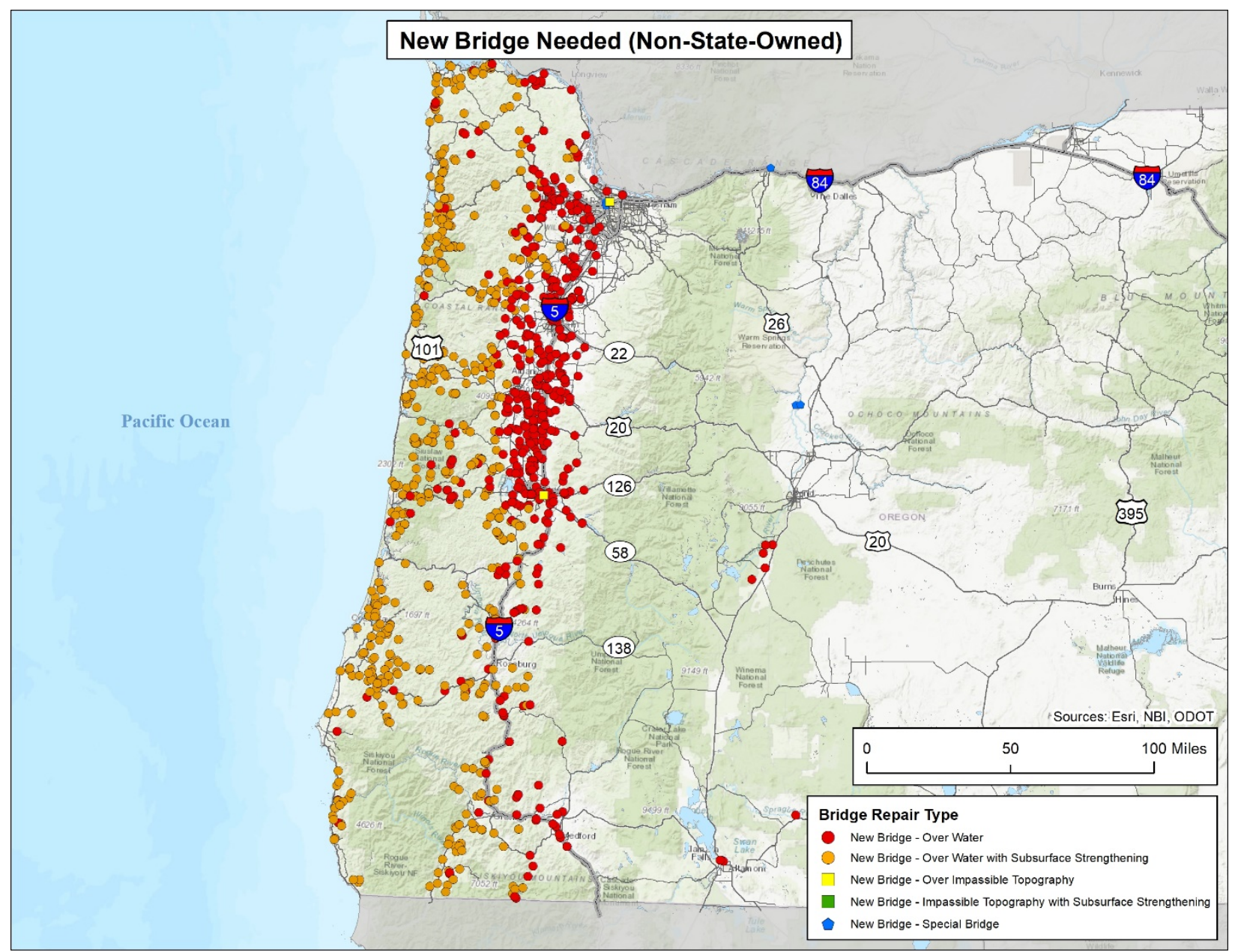

FIGURE 15.-Non-state-owned Bridges in Oregon Projected by the BSST to Experience Severe Damage Requiring Construction of a New Bridge after the CSZ Scenario Earthquake. 


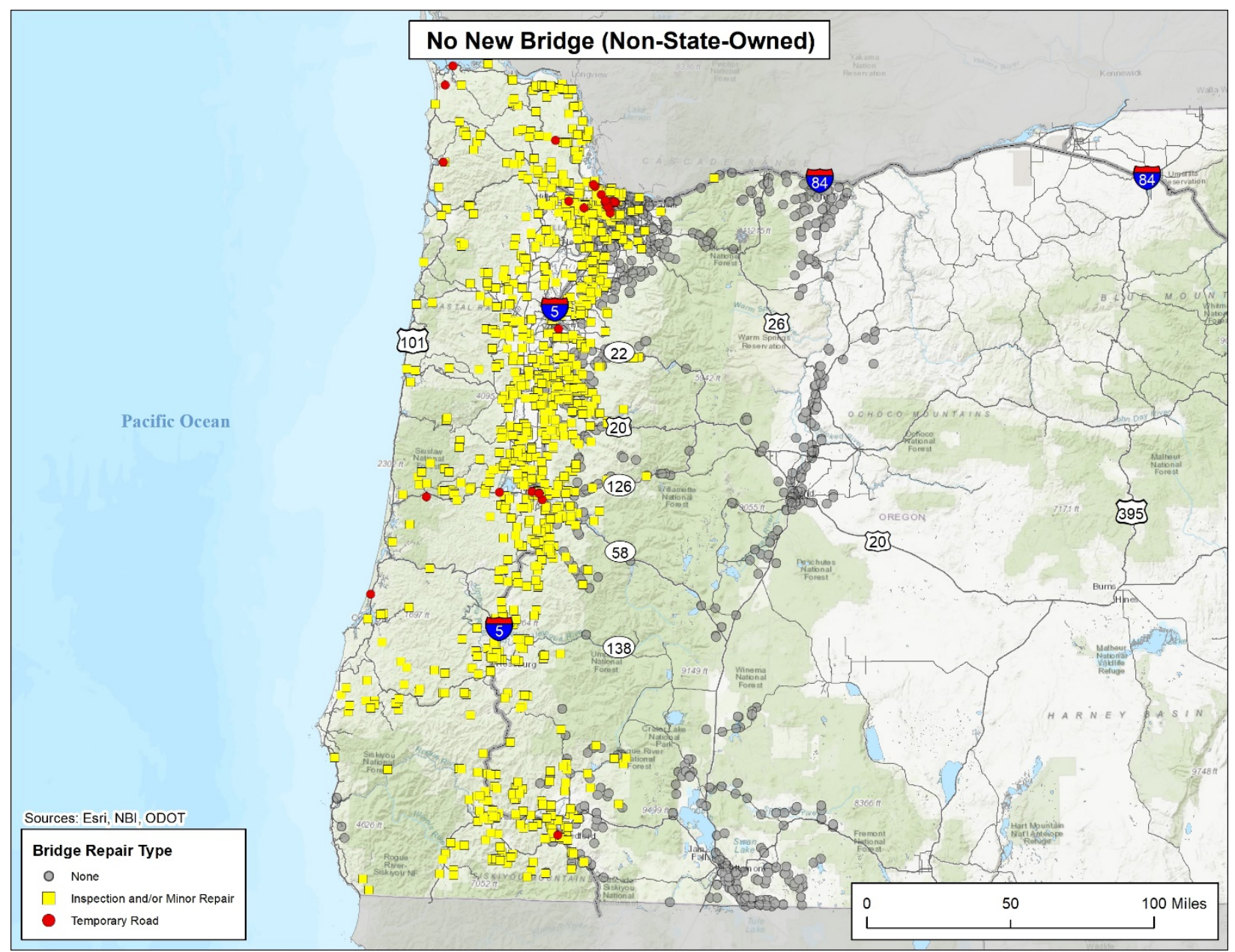

FIGURE 16.-Non-state-owned Bridges in Oregon Projected by the BSST to Not Require the Construction of a New Bridge after the CSZ Scenario Earthquake.

\section{Bridge Reopening Times}

Table 5 provides the projected reopening times that would be necessary to construct a temporary bypass road, conduct bridge rehabilitation repairs, or build a replacement bridge. While 1,335 bridges (23.6 percent of assessed bridges) are projected to sustain no damage-of which 522 are state-owned (21.1 percent of assessed state-owned bridges) and 813 are non-state-owned (25.6 percent of assessed non-state-owned bridges)-and therefore have no projected delay in reopening from a structural perspective, it is important to note that ODOT may still choose to conduct inspections on some structures, which could cause minor delays in reopening. Nonetheless, 2,066 bridges (36.6 percent of bridges assessed) could be reopened within the first month after the earthquake occurs after inspections and minor repairs are made or temporary roads are constructed to bypass severely damaged bridges. Of these bridges, 859 bridges are state-owned (34.8 percent of assessed state-owned bridges) and 1,207 are non-state-owned (38.0 percent of assessed non-stateowned bridges). Conversely, 1,530 bridges, or nearly 27 percent of the bridges evaluated (of which 682 are state-owned and 848 are non-state-owned), would require more than 1 year to reopen. 
TABLE 5.-Projected Bridge Reopening Times after CSZ Scenario Earthquake.

\begin{tabular}{|l|r|}
\hline Reopening Time & Number of Bridges \\
\hline None & 1,335 \\
\hline $1-30$ days & 2,066 \\
\hline $1-3$ months & 297 \\
\hline $3-6$ months & 51 \\
\hline $6-12$ months & 367 \\
\hline $1-2$ years & 1,231 \\
\hline$>2$ years & 299 \\
\hline
\end{tabular}

Figures 17 and 18 show the geographical distribution of state and non-state-owned bridges in Oregon, respectively, according to their reopening times. Reopening times are greatest along and west of the $1-5$ corridor, moderate between the $1-5$ corridor and the Cascade Mountains, and minimal east of the Cascade Mountain range.

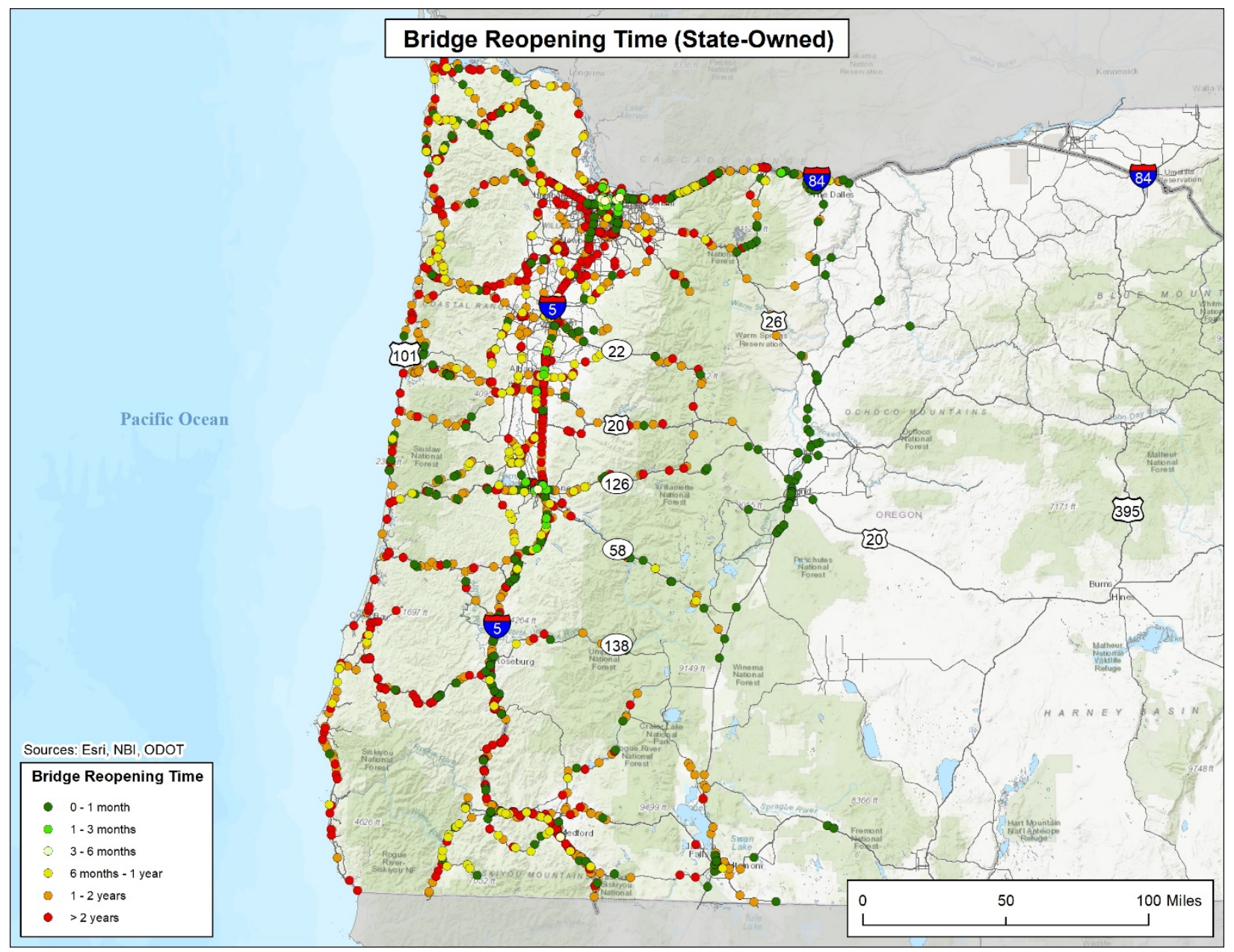

FIGURE 17.-BSST Projected Reopening Times for State-owned Bridges in Oregon after the CSZ Scenario Earthquake. 


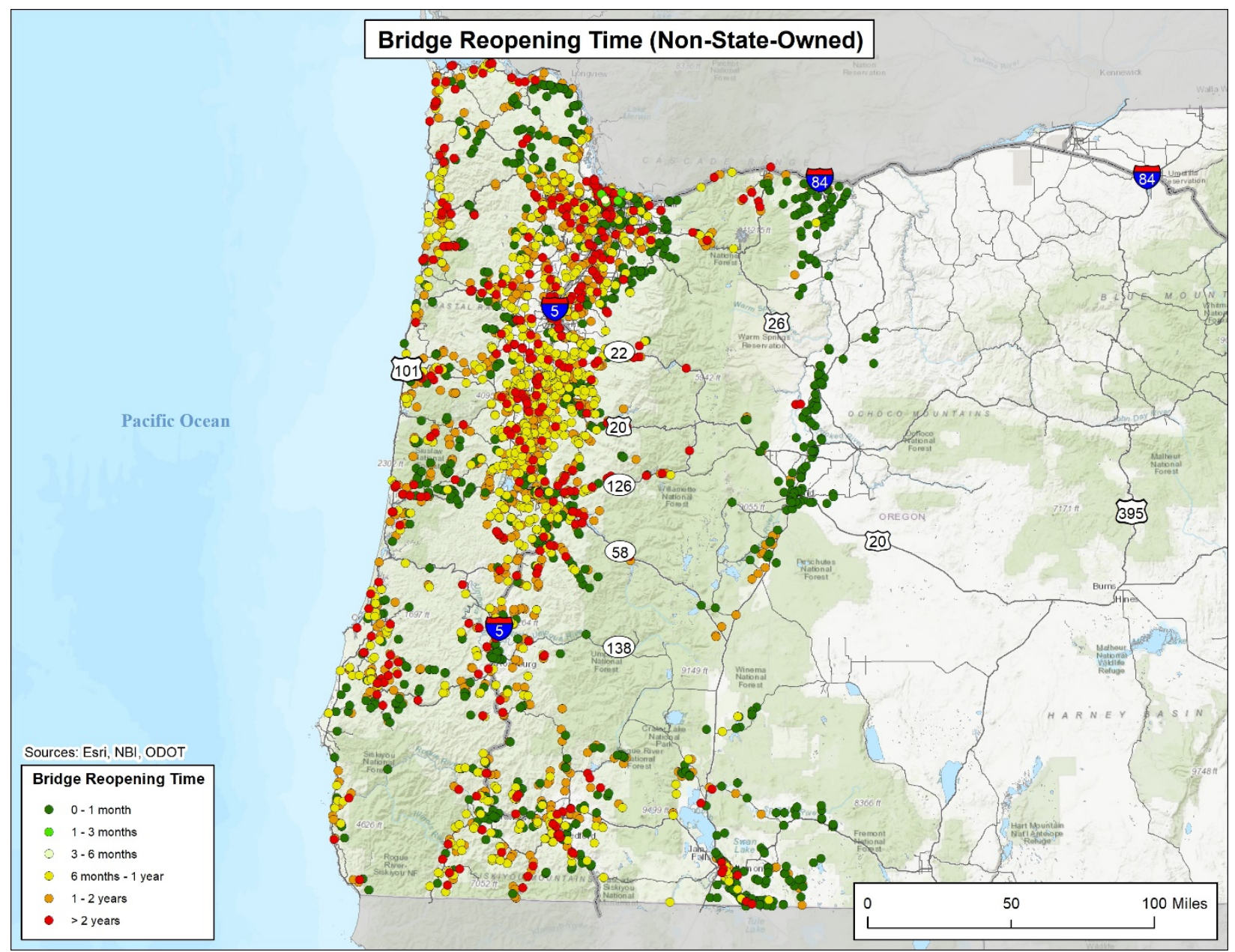

FIGURE 18.-BSST Projected Reopening Times for Non-state-owned Bridges in Oregon after the CSZ Scenario Earthquake. 


\section{Conclusions and Future Use}

Argonne initially developed the BSST to assess the potential impacts of a CSZ earthquake to highway bridges in Washington State at a system-level as part of the 2017 Washington State Transportation Systems RRAP project. Following subsequent discussions with ODOT bridge engineers and bridge engineering SMEs, Argonne refined and used the BSST to assess the potential impacts of a CSZ earthquake to bridges in Oregon at a system level as part of the 2018 Oregon Transportation Systems RRAP project. The results provided in this technical report identify the damage levels, damage types, repair types, and reopening times associated with 5,646 bridges located in Western and Central Oregon that Argonne evaluated for this RRAP project. Understanding that this analysis likely constitutes a "worst-case scenario" with respect to bridge damage, the results project that the majority of bridges in Oregon will experience moderate to severe damage resulting from a CSZ earthquake. While the majority of bridges that experience damage could reopen within 1 year of the earthquake, a substantial number of those bridges (27.1 percent) are projected to take more than a year to reopen-in many cases 2 or more years. The results also project that while many bridges may be reopened after either minor repairs/inspections or the construction of a temporary bypass road, a substantial number of more severely damaged bridges (1,877 structures) span bodies of water or impassible terrain, or have special bridge designs, and will require complete replacement prior to reopening. This suggests that significant gains in roadway corridor reopening times could be gained by focusing on retrofits or upgrades to these more vulnerable bridges that span rivers and other bodies of water or impassible terrain.

This tool is primarily intended to inform regional highway prioritization for emergency response activities in the broader Oregon Transportation Systems RRAP project (CISA 2021). However, the BSST provides a useful evaluation methodology that could be applied to other regional emergency preparedness and infrastructure assessment studies, including studies of bridge infrastructure to other potential seismic events within the region, or at varying jurisdictional levels (i.e., county, local). The BSST also uses currently available seismic, seismically induced secondary hazard and infrastructure information. As new seismic information becomes available, or as secondary hazards (e.g., landslides, avalanches) become characterized more comprehensively, such information could be integrated into the current BSST methodology. Similarly, as seismic retrofit activities or other infrastructure improvement projects continue throughout Oregon, or as new infrastructure are built, it will be important that the infrastructure data integrated in the BSST also be updated periodically. Doing so will ensure that planners and infrastructure managers maintain the most current and complete understanding of the network-level seismic risks of a CSZ event to Oregon roadways. 


\title{
Acronyms and Abbreviations
}

\author{
AASHTO \\ American Association of State Highway and Transportation Officials \\ Argonne \\ Argonne National Laboratory \\ BSST \\ Bridge Seismic Screening Tool \\ CISA \\ CREW \\ Cybersecurity and Infrastructure Security Agency \\ CSZ \\ Cascadia Region Earthquake Workgroup \\ Cascadia Subduction Zone \\ DEM \\ digital elevation model \\ DHS \\ U.S. Department of Homeland Security \\ DOGAMI \\ Oregon Department of Geology and Mineral Industries \\ ft. feet \\ । \\ Interstate \\ m \\ meter \\ ODOT \\ Oregon Department of Transportation \\ OEM \\ Oregon Office of Emergency Management \\ PGA \\ peak ground acceleration \\ PGD \\ peak ground displacement \\ $\mathrm{RC}$ \\ reinforced concrete \\ RRAP \\ Regional Resiliency Assessment Program \\ $S$ \\ second \\ SME \\ subject matter expert \\ USGS \\ U.S. Geological Survey \\ WEMD \\ Washington Emergency Management Division \\ WSDOT \\ Washington State Department of Transportation
}




\section{References}

Bazáez Gallardo, and Ramiro Andrés Gabriel, 2017, Achieving Operational Seismic Performance of RC Bridge Bents Retrofitted with Buckling-Restrained Braces, Portland State University, February 13, https://pdxscholar.library.pdx.edu/open_access_etds/3476/, accessed July 16, 2021.

Bergerson, Josh, Thomas Wall, Scott Schlueter, DeWayne Wilson, and Glen Scroggins, 2019, Washington State Highway Bridge Seismic Screening Tool (BSST), Argonne National Laboratory, December, https://publications.anl.gov/anlpubs/2020/01/157924.pdf, accessed July 16, 2021.

Brandenberg, Scott J., Jian Zhang, Pirooz Kashinghandi, Yili Huo, and Minxing Zhao, 2011, Demand Fragility Surfaces for Bridges in Liquefied and Laterally Spreading Ground, Pacific Earthquake Engineering Research Center, March, https://peer.berkeley.edu/sites/default/files/webpeer-201101-scott j. brandenberg jian zhang pirooz kashighandi yili huo and minxing zhao.pdf, accessed July 16, 2021.

CISA, 2021, Resiliency Assessment: Oregon Transportation Systems.

CISA, 2019, Resiliency Assessment: Washington State Transportation Systems.

CREW, 2013, Cascadia Subduction Zone Earthquakes: A Magnitude 9.0 Earthquake Scenario. Olympia, WA: Cascadia Region Earthquake Working Group.

Esri, undated, "Add Surface Information (3D Analyst)," https://pro.arcgis.com/en/proapp/latest/tool-reference/3d-analyst/add-surface-information.htm, accessed July 16, 2021.

FHWA (Federal Highway Administration), 2012, "Memorandum: Action: Clarificatoin of Requirements for Fracture Critical Members." U.S. Department of Transportation, June 20, https://www.fhwa.dot.gov/bridge/120620.cfm, accessed May 2018.

FHWA, 2018, "National Bridge Inventory (NBI)." Federal Highway Administration United States Department of Transportation, https://www.fhwa.dot.gov/bridge/nbi.cfm, accessed May 2018.

Fu, Gongkang, and Pang-jo Chun, 2013, Skewed Highway Bridges. Detroit, Ml: Center for Adganced Bridge Engineering, Department of Civil \& Environmental Engineering, Wayne State University.

ODOT (Oregon Department of Transportation), 2009, Seismic Vulnerability of Oregon State Highway Bridges: Mitigation Strategies to Reduce Major Mobility Risks, November, https://www.oregon.gov/odot/Programs/ResearchDocuments/2009_Seismic_Vulnerability.pdf, accessed July 16, 2021.

PNSN (Pacific Northwest Seismic Network), undated, "Cascadia Subduction Zone," https://pnsn.org/outreach/earthquakesources/csz, accessed May 2018.

Oregon Spatial Data Library, 2016, "Oregon 10m Digital Elevation Model (DEM)," https://spatialdata.oregonexplorer.info/geoportal/details;id=7a82c1be50504f56a9d49d13c7b4d9 aa, accessed July 16, 2021.

Priest, George R., Robert C. Witter, Y. Joseph Zhang, Kelin Wang, Chris Goldfinger, Laura L. Stimely, John T. English, Sean G. Pickner, Kaleena L.B. Hughes, Taylore E. Wille, and Rachel L. Smith, 2013, 
Tsunami Inundation Scenarios for Oregon, Oregon Department of Geology and Mineral Industries, https://www.oregongeology.org/pubs/ofr/0-13-19.pdf, accessed July 16, 2021.

USGS (U.S. Geological Survey), 2017, "M 9.0 Scenario Earthquake - Cascadia M9.0 Scenario (Mean Value),"

https://earthquake.usgs.gov/scenarios/eventpage/gllegacycasc9p0expanded se\#shakemap?sourc $\underline{e=u s \& c o d e=g l l e g a c y c a s c 9 p 0 e x p a n d e d \_s e}$, accessed May 2018.

USGS, undated, "Cascadia Subduction Zone: Two Contrasting Models of Lithospheric Structure." https://earthquake.usgs.gov/data/crust/cascadia.php, accessed May 2018 (link no longer active).

WSDOT, undated, "Scour Repairs." Washington State Department of Transportation, https://www.wsdot.wa.gov/Bridge/Reporting/ScourRepairs.htm, accessed May 2018 (link no longer active). 


\section{Appendix A: Major Revisions from BSST Version 1 to BSST Version 2}

Following delivery of the first version of the BSST to key stakeholders, Argonne made the following model enhancements based on critical feedback from bridge engineers and bridge engineering and geotechnical SMEs:

- Based on recommendations from bridge engineering SMEs, the assessment of damages due to seismic forces was refined to include a moderate seismic damage level. This was operationalized by considering two bridge design levels for all bridges: operational and lifesafety (ODOT 2009). The operational design level corresponds to a hazard level up to which bridges are expected to experience minor damage and thus remain operational, while the life-safety design level corresponds to a hazard level up to which bridges have a very low probability of collapse. Since bridges in Oregon built before 2004 were designed considering only a single seismic hazard design level, it was assumed that this design level corresponds to the operational design level. Furthermore, this value was scaled by an assumed scaling factor of 1.4 to estimate a seismic hazard level corresponding to a life-safety design level.

0 In the initial BSST implementation, bridges with pier walls and single-span bridges were assumed to experience lower damage due to seismic loading when exposed to peak ground acceleration (PGA) exceeding a bridge's seismic design PGA. In the revised BSST, any bridge with pier walls or a single span which are projected to experience a PGA from the CSZ scenario earthquake exceeding its life-safety design level is projected to experience moderate damage. Likewise, any bridge with pier walls or a single span which is projected to experience a PGA from the CSZ scenario earthquake exceeding its operational design level but less than its life-safety design level is projected to experience minimal damage.

- BSST V2 no longer includes a long-duration shaking capacity reduction factor. The original BSST included a long-duration amplification factor that increased the projected PGA for a fulllength rupture CSZ earthquake scenario to account for the expected increased number of inelastic deformation cycles during the CSZ earthquake that is projected to last for 3-6 minutes, significantly longer than the typical earthquake duration for which seismic design codes have primarily been developed. During the 2018 Oregon Transportation Systems RRAP project, bridge engineering SMEs recommended removing this amplification factor since older bridges are generally brittle (and thus the number of inelastic cycles is unlikely to increase damage) while longer duration shaking is expected to have minimal effect on newer bridges.

- The methodology for assessing liquefaction was completely overhauled based on feedback from bridge engineering SMEs. The revised methodology assesses peak ground displacement (PGD) at bridge locations and evaluates bridge liquefaction damage using fragility curves that are a function of liquefaction-induced PGD.

- The original BSST implementation considered an inherent seismic capacity of bridges to withstand a PGA of $0.15 \mathrm{~g}$ regardless of the year of bridge design, even if the bridge was designed without consideration of seismic loads. Based on discussions with ODOT bridge engineers and bridge engineering SMEs, bridges designed with seismic detailing (bridges built in 1976 or later in Oregon) are assumed to have an inherent seismic capacity of $0.2 \mathrm{~g}$, corresponding to an operational design level. This assumed inherent operational seismic design capacity was scaled by 1.4 to estimate an assumed inherent life-safety seismic design capacity for bridges designed with seismic detailing. The inherent seismic capacity of bridges designed without seismic detailing was estimated from fragility curves for reinforced 
concrete (RC) bridge bents exposed to long-duration shaking (as expected during a full-length CSZ earthquake), developed in Bazáez Gallardo (2017).

- Based on recommendations from ODOT, a special consideration was added to the BSST for precast concrete piles which are assumed to experience severe damage when exposed to a PGA seismic hazard exceeding $0.1 g$.

- The assumed reopening time for bridges projected to experience moderate damage was revised from 2 weeks to 4 days. 


\section{Argonne}

\section{Decision and Infrastructure Sciences Division}

Argonne National Laboratory

9700 South Cass Avenue, Bldg. 203

Argonne, IL 60439

www.anl.gov

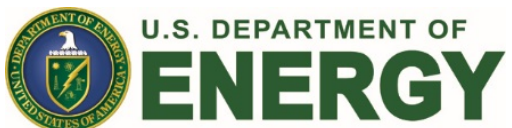

Argonne National Laboratory is a U.S. Department of Energy laboratory managed by UChicago Argonne, LLC 